Lexis Vol. XLV (1) 2021: 5-76

\title{
El uso de vuestro en el español de Cuzco: nuevos datos y nuevas perspectivas de estudio
}

\author{
Philipp Dankel \\ https://orcid.org/0000-0001-7357-6877 \\ Universidad de Basilea \\ Philipp.dankel@unibas.ch \\ Miguel Gutiérrez Maté \\ https://orcid.org/0000-0001-7971-9496 \\ Universidad de Angsburgo \\ Miguel.Gutierrez.Mate@philhist.uni-augsburg.de
}

\section{RESUMEN}

Este trabajo avanza en la explicación del uso productivo de vuestro en el español de Cuzco (Perú) sobre la base de nuevos datos de trabajo de campo. Demostramos su significado exclusivamente plural y su integración en el paradigma gramatical de ustedes. Analizamos su valor discursivo de contraste grupal y su valor socioindexical de buena formación. Finalmente, planteamos propuestas provisionales sobre tres aspectos: (1) la extensión diatópica del fenómeno en otras áreas del espacio andino y extraandino; (2) su evolución diacrónica a partir de las combinaciones de los paradigmas de vosotros y ustedes; y (3) la actuación indirecta del contacto lingüístico, considerando el uso contrastivo de vuestro como una estrategia de compensación para categorías comunicativas relevantes regionalmente, gramaticalizadas en el quechua sureño.

Palabras clave: posesivos, formas de tratamiento plurales, español andino, identidad “mestiza”, Cuzco

https://doi.org/10.18800/lexis.202101.001 
The use vuestro in Cusco Spanish: New Data and New Study Perspectives

\section{Abstract}

This article advances in explaining the productive use of vuestro in Cusco Spanish (Peru), based on new fieldwork data. We highlight its plural meaning and its systematic integration into the paradigm of ustedes. We analyze its discursive value for contrasting groups with each other and its social indexicality as a marker of literacy. Finally, we outline three proposals on the aspects still to be studied: (1) the diatopic diffusion of PL vuestro in other parts of the Andean region (and outside the Andes); (2) its diachronic evolution (as a result of the hybridization of the paradigms of vosotros and ustedes); and (3) the indirect effect of language contact (the contrastive use of vuestro as a compensation strategy for regionally relevant communicative categories, grammaticalized in Southern Quechua).

Keywords: possessives, plural forms of address, Andean Spanish, "mestizo" identity, Cusco

\section{Introducción}

Este trabajo avanza en la explicación del uso de vuestro/a/os/as (en lo sucesivo, simplemente, vuestro) como forma de posesivo de la segunda persona plural (2P.PL) en el español de la región de Cuzco (Perú), donde se presenta integrado en el paradigma gramatical de ustedes. Para referirnos a este paradigma — constituido por el pronombre independiente ustedes, los clíticos los las (acusativo) / les (dativo) / se (reflexivo/recíproco/alomorfo del dativo), las desinencias verbales de 3P.PL, y el posesivo vuestro- hablaremos de "paradigma-u/v", por oposición al "paradigma-u", correspondiente al paradigma de ustedes con todas las formas propias de la 3P.PL, incluyendo entonces el posesivo su/s (en lo sucesivo, simplemente, su), y al "paradigma-v", correspondiente al paradigma gramatical de vosotros, con las formas etimológicas de 2P.PL.

En el Cuzco, la forma vuestro es de uso común: si bien en algunos casos su uso se podría considerar "formulaico", restringido a 
contextos muy específicos, como en el final del ejemplo (1), una fórmula estereotipada con la que el hablante asegura a los oyentes que la acción o evento recién realizado se ha destinado a complacerlos, otros ejemplos demuestran que el uso de vuestro es completamente productivo (ejemplo 2), sirviendo entonces para poner de relieve algún tipo de relación contrastiva entre las acciones, estados o actitudes del hablante - $\mathrm{O}$, generalmente, las del grupo en el que se posiciona el hablante- y los del destinatario plural (un contraste que, no obstante, se puede plantear con finalidad persuasiva para representar en última instancia una comunión de intereses o actitudes); hablaremos en estos últimos casos de usos “estratégicos”.

(1) Chicos, muchas gracias por estar en mi pueblo, en mi país, les doy la bienvenida nuevamente y espero que haya sido de vuestro agrado (guía turístico, 30 años, reproduciendo las palabras que utiliza para finalizar sus tours, Ollantaytambo, Cuzco / DGM201919)

(2) Quiero agradecerles por vuestro respaldo. No los defraudaré. Con el mismo temple que pido su apoyo, también les manifiesto que seremos todos [...] guardianes del patrimonio cultural y humano (alcaldesa de la Municipalidad del Cuzco en su mensaje televisado de Fiestas Patrias, 28.7.2020)

Es posible que algunos hablantes solo utilicen activamente el vuestro como parte de frases hechas (uso formulaico), pero pensamos que la mayoría de los cuzqueños emplean tanto vuestro como su conforme a sus estrategias lingüísticas: de hecho, ya en (2), ejemplo cuyo análisis retomaremos más adelante, tenemos una primera muestra de la alternancia entre las dos formas (vuestro respaldo vs. su apoyo). Incluso, no descartamos que haya un tercer grupo de hablantes para los que el uso de vuestro no responda a estrategia retórica ninguna - hablantes para los que vuestro constituiría la forma de posesivo de 2P.PL por antonomasia-. Sin embargo, nos faltan aún datos fiables para demostrar definitivamente este

\footnotetext{
1 Este ejemplo está tomado de la colección de datos que recopilamos en nuestro trabajo de campo en diciembre de 2019. Utilizaremos la etiqueta DGM2019 para referirnos a los ejemplos de estas entrevistas (v. $\$ 2$ ).
} 
último aspecto (contamos apenas con las percepciones de unos pocos hablantes en este sentido); además, aunque futuras investigaciones llegaran a demostrar que vuestro es, en efecto, la forma tradicionalmente cuzqueña, cierto grado de variación vuestro-su sería esperable en cualquier caso, ya que el uso limeño (y panamericano) con su entra también con fuerza en la región y parece influir, consciente o inconscientemente, en la selección de formas lingüísticas por parte de algunos hablantes, sobre todo, de los jóvenes. En nuestra opinión, la "variación libre" —al menos, con respecto al fenómeno estudiado aquí (vuestro vs. su) — no existe: de hecho, con muy pocas excepciones, los usos de vuestro presentan un valor discursivo y/o socioindexical marcados, que definiremos más adelante.

Al comenzar hablando de "avance" lo hicimos teniendo en mente otro artículo nuestro (Dankel y Gutiérrez Maté 2020), que constituyó la primera monografía sobre el tema y a cuyas propuestas centrales volveremos en distintos puntos de este trabajo. No obstante, es necesario admitir que seguimos dejando muchas preguntas abiertas, tanto con respecto a la caracterización estructural y variacional del fenómeno como con respecto a sus orígenes, por lo que las páginas que siguen deben considerarse una instantánea de un programa de investigación en marcha en la que resumimos los aspectos ya estudiados y esbozamos algunas propuestas sobre los aspectos pendientes de estudio. En cualquier caso, ambos trabajos presentan evidencias suficientes para demostrar que el uso de vuestro en la región del Cuzco es un fenómeno complejo que no se relaciona solo (ni siquiera, primariamente) con la necesidad de desambiguación frente a su, ni con los discursos ceremoniosos, dos ideas que podrían corresponder, quizá, a la primera intuición de algunos y que han sido expuestas con anterioridad en la muy exigua bibliografía sobre el tema, como veremos.

En lo que sigue, establecemos primero nuestro punto de partida (\$2): para ello, recopilamos los resultados de Dankel y Gutiérrez Maté (2020) y presentamos de una sola vez una serie de ejemplos -nuevos datos recolectados, sobre todo, durante nuestro trabajo de campo más reciente en diciembre del 2019_, a los que iremos haciendo referencia en el progreso del trabajo (etiquetados como 
DGM2019). El resto del artículo está dedicado en su mayor parte a caracterizar el vuestro cuzqueño: en $\$ 3$ damos cuenta de sus propiedades estructurales y sistémicas fundamentales (referencia exclusivamente plural e integración completa en el paradigma de ustedes), así como de su idiomaticidad (no solo restringido a una serie de tradiciones discursivas específicas), de modo que todas estas propiedades combinadas hablan a favor de una cierta especificidad del uso cuzqueño en comparación con el empleo más o menos marginal de vuestro en otras regiones de América; por su parte, en $\$ 4$ se analizarán los factores que, conforme a los datos disponibles hasta ahora, determinan su uso en detrimento de la variante $s u$ - si bien nuestro análisis no puede trascender, a día de hoy, la fase cualitativa-, deteniéndonos en explicar su valor discursivo de “contraste” ( $\$ 4.1)$ y, como base frecuente de este, su valor semántico especial dentro de la pluralidad (referencia específica, más "grupal" que simplemente "plural”, con interpretación distributiva) ( $\$ 4.2)$, así como su carácter socioindexical de "buena formación” o incluso de "calidad personal" (\$4.3). Una vez expuestas las características del vuestro cuzqueño por lo que respecta al sistema $(\mathbb{3})$ y al uso $(\mathbb{4})$, dedicamos la parte final del artículo $(\mathbb{5})$ a esbozar una serie de futuros desarrollos en el estudio sociohistórico de este fenómeno, a través de una serie de interrogantes para las que, en el mejor de los casos, tenemos apenas respuesta parcial; concretamente, planteamos el problema de la extensión diatópica de vuestro como posesivo de 2P.PL (tanto dentro y fuera de la región cuzqueña como dentro y fuera del Perú, ya que el paradigma-u/v parece registrarse ocasionalmente en otras variedades) (\$5.1), el de la antigüedad y conformación histórica del paradigma-u/v $(\$ 5.2)$ y el de su interrelación con aspectos culturales e identitarios andinos $y$, particularmente, cuzqueños, entre los que, evidentemente, se cuenta el multilingüismo español/quechua (a este respecto, dado que en ningún caso se pudo tratar de una transferencia directa, indicaremos en qué términos exactos cabe entender la actuación de un posible contacto lingüístico) (\$5.3). Cierran el trabajo unas palabras finales en las que hacemos balance de los principales hallazgos (\$6). 
2. Punto de partida: resumen de resultados anteriores y nuevos datos

La base empírica de Dankel y Gutiérrez Maté (2020) fue la observación directa del fenómeno durante nuestra primera visita al Cuzco en 2016, completada después con distintos materiales de radio, televisión, foros en la red y Youtube. El uso del vuestro en el español de la región nunca había sido estudiado en profundidad, a pesar de ser un fenómeno bastante común en la región. Apenas hallamos rápidas menciones al tema en Caravedo (1996: 61, 2005: 28-29), y Rivarola (2005: 36) y seguimos sin conocer otras referencias al fenómeno, si bien a esta corta lista bibliográfica podrían añadirse ahora otros trabajos que, indirectamente, resultan de utilidad para nuestros intereses aquí, como los de Caravedo (2019) y Hildebrandt (2012): el primer trabajo describe cómo el uso del paradigma completo de vosotros, según el uso antiguo colonial, se adapta y circunscribe después a ciertos dominios formales en el siglo XIX (v. también Bertolotti 2007, 2020), el cual existe aún en la actualidad; el segundo se dedica específicamente a la forma posesiva (vuestro), pero lo hace desde una perspectiva prescriptivista, limitándose a condenar el uso 'incompleto' del paradigma de vosotros en el habla culta peruana (o en "lo que debiera serlo"). Volveremos con más detalle a estos trabajos en $\$ 3.2$.

En nuestro anterior artículo introdujimos ya la distinción, vista arriba, de dos grandes grupos de usos, formulaicos y estratégicos, siendo estos últimos los más interesantes para su análisis lingüístico. Llegamos a la conclusión de que, aunque responda a condicionamientos discursivos (con base semántica y/o estructural-informacional) relacionados con la noción de contraste, la preferencia última de vuestro sobre $s u$ es una cuestión de variedades lingüísticas: es decir, es solo en ciertas variedades en las que el contraste entre los participantes plurales del acto de comunicación se vehicula por medio del uso estratégico de vuestro. Todos estos aspectos los desarrollaremos aquí con más detalle y nuevos testimonios. 
En aquella ocasión, observamos la dependencia de factores situacionales que constituyen la lengua escrita en sentido concepcional o distancia comunicativa (según la definición de la tradición alemana de Koch y Oesterreicher ([1990] 2011:7). Reconocemos ahora, no obstante, que esta consideración estuvo parcialmente condicionada por el corpus que empleamos entonces y que el uso de vuestro no es exclusivo de la distancia comunicativa: así, más recientemente, lo hemos hallado también en situaciones de inmediatez en el ámbito privado y familiar (v. ejemplos (3)-(5) más abajo). Con todo, seguimos pensando que, por una parte, algunos hablantes en verdad emplean el vuestro estratégico predominantemente en discursos de la distancia comunicativa y que, por otra parte, los usos formulaicos integran —o incluso constituyen por sí mismos- tradiciones discursivas que cristalizaron originalmente en el ámbito de la distancia comunicativa (y a menudo siguen perteneciendo a este) (v. Kabatek 2005 para una definición abarcadora de la noción de tradición discursiva y para la gestación y evolución de este concepto en la lingüística de variedades alemana).

Por lo demás, gran parte de aquel trabajo se dedicó a examinar los orígenes del uso de vuestro en español cuzqueño, para lo que planteamos varias hipótesis (en buena medida, compatibles entre sí), incluyendo la de una posible transferencia nocional o discursiva del quechua. En $\$ 5.2$ y $\$ 5.3$ recuperaremos algunos de esos planteamientos y los completamos con una nueva cala en textos antiguos; no obstante, remitimos al lector interesado a Dankel y Gutiérrez Maté (2020: 328-352) para una exposición detallada de las distintas posibilidades diacrónicas. Cabe advertir que, como en aquella ocasión, nos sigue pareciendo que el turismo español, el consiguiente contacto con el uso peninsular de vosotros y su paradigma y el posible deseo de agradar a turistas de esta nacionalidad no son factores determinantes del fenómeno estudiado: no solo el español peninsular no emplea el paradigma-u/v, sino que, a fin de cuentas, solo el 2,1\% de los turistas extranjeros en Cuzco son de origen español, una cifra bastante inferior al $11 \%$ de turistas procedentes de otros países hispanoamericanos (según datos del 
Boletín Estadístico de Turismo de 2014 de la Dirección General de Comercio y Turismo (Dircetur)). Además, no esperamos que el frecuente uso de vuestro en discursos de instituciones gubernamentales regionales o en emisoras de radio cuzqueñas tenga en cuenta a posibles alocutarios españoles (ni de otras regiones).

Para este nuevo trabajo manejamos datos procedentes, sobre todo, de nuestro trabajo de campo en 2019, dedicado exclusivamente a registrar y estudiar este fenómeno ${ }^{2}$. Durante nuestra estancia entrevistamos a 33 informantes de diferentes perfiles sociolingüísticos, sobre todo en la ciudad de Cuzco —si bien algunos eran migrantes llegados de distintas áreas rurales del departamento- y en el poblado de Ollantaytambo; además, asistimos también a diversos eventos públicos (celebraciones litúrgicas, discursos del Día Nacional de la Policía, presentación en público de una nueva ordenanza municipal, etc.) y tuvimos acceso a diversas fuentes escritas (también algunas de los dos siglos pasados, incluyendo la sección de hemeroteca de la Biblioteca Municipal del Cuzco). El objetivo era tener una perspectiva más amplia sobre el fenómeno para poder diseñar y preparar la siguiente fase de recopilación de datos, prevista para $2021^{3}$. En las entrevistas, elicitábamos

\footnotetext{
2 Para la organización de nuestro trabajo de campo en el Cuzco, previo paso por Lima, contamos con el apoyo de nuestros colegas y amigos de la PUCP, Álvaro Ezcurra y Carlos Garatea Grau, así como con la financiación de nuestras respectivas universidades: el Reisefonds für den akademischen Nachwuchs de la Universidad de Basilea y el programa Kostenübernabme/-bezuschussung für Reisen bzw. Besuche zur Anbabnung und Pflege internationaler Kooperationen del Vicerrectorado de Relaciones Internacionales de la Universidad de Augsburgo. Vaya nuestro agradecimiento para los colegas y las instituciones mencionadas, sin cuya cooperación este trabajo sería imposible.

3 Valga un ejemplo para mostrar cómo algunas partes del trabajo de campo no pudieron llevarse a cabo como esperábamos, pudiendo esto deberse a problemas imposibles de prever sin una experiencia in situ: teniendo noticias indirectas de que el uso de vuestro aparece en los "discursos de instrucción”, que se celebran diariamente (en doble turno) en el patio del edificio de la policía local, en los que un alto mando habla durante casi 30 minutos a los demás policías, nos propusimos presenciar y grabar estos discursos. Sin embargo, a pesar de que fuimos recibidos amablemente por los más altos cargos (incluyendo el General de la Policía Nacional del Perú con el cargo de jefe de la Macro-región Policial de Cuzco), nuestra petición fue rechazada — de manera muy comprensible, en realidad - por las autoridades locales, primero, y por las regionales,
} 
ejemplos buscando situaciones en las que los informantes debieran dirigirse a nosotros dos, además de pedirles que imaginaran qué palabras utilizarían en tal o cual contexto (¿Qué diría si...?). En el momento de producir esos ejemplos los hablantes solo eran conscientes de que nuestro proyecto se ocupaba de las especificidades culturales y comunicativas de la región del Cuzco; generalmente no era solo hasta el final de la entrevista cuando revelábamos que nuestro interés principal consistía apenas en entender el uso de vuestro, lo que llevaba, a su vez, a elicitar percepciones y valoraciones metalingüísticas adicionales, generalmente sobre la base de un cuestionario con frases concretas que habíamos registrado anteriormente. Cuando los ejemplos estén tomados de estas entrevistas, en cualquiera de sus partes, utilizaremos la etiqueta DGM2019 (por lo demás, las fuentes de los distintos ejemplos están indicadas entre paréntesis). Hay que advertir, por último, que, en la medida en que presentamos testimonios y juicios de valor de los propios informantes en varios puntos del trabajo, este supone también, indirectamente, una modesta aportación al campo de la dialectología perceptiva (Preston 1999); por lo general, no obstante, tales percepciones nos sirven como datos de control de los usos documentados en las entrevistas para, conjuntamente, modelar nuestra interpretación de los hechos lingüisticos (Oesterreicher 2010).

En el estado actual de la investigación, estamos en disposición de hacer dos planteamientos fundamentales en relación a la especificidad del fenómeno estudiado:

(a) el uso de vuestro a la manera cuzqueña, donde se ha constituido un paradigma estable de 2P.PL del tipo "ustedes - les/los - desinencias de 3P.PL - vuestro", se presenta como un fenómeno diferente

después (en parte movidos por alguna experiencia negativa reciente con periodistas que habían grabado y publicado, en condiciones algo distintas de las acordadas, la actividad cotidiana de un grupo de policías). Sin embargo, como ellos mismos nos indicaron, nuestras grabaciones habrían sido posibles si hubiéramos conseguido una autorización ministerial: cuando finalmente obtuvimos esta información, sin embargo, resultó ser ya demasiado tarde para regresar a Lima, elaborar la solicitud, esperar su resolución, y regresar de vuelta al Cuzco. 
del descrito en otras variedades hispanoamericanas (al menos, si nos basamos en la bibliografía existente sobre estas otras variedades): por una parte, en lo cualitativo, es diferente del uso de vuestro como parte del paradigma completo de vosotros, el cual se presenta marginalmente en algunos contextos específicos en diversas zonas de América (Morgan y Schwenter 2016, en prensa); por otra parte, en lo cuantitativo, es mucho más frecuente que el empleo ocasional y "reservado casi exclusivamente a la lengua escrita" de vuestro -integrado, este sí, en el paradigma de ustedes - al que Fontanella de Weinberg (1999: 1403-4) se refirió de pasada como posible alternativa al posesivo plural $s u(s)$ en sus esquemas de tratamientos II-IV.

(b) se trata de un fenómeno en el que intervienen muchos niveles de variación, lo que hace que presentar una explicación unívoca de él resulte tarea imposible: por una parte, la alternancia vuestro/su(s) se puede ver como una variable lingüística, que parece ser dependiente de variables explicativas de tipo semántico, pragmático y estructuralinformativo; por otra parte, los condicionamientos de esta variación intrasistemática difieren en función de las variedades diatópicas, diastráticas, diafásicas, y diaconcepcionales (Koch y Oesterreicher [1990] 2011: 16-18) y de las idiosincrasias de cada hablante/grupo de hablantes. No podemos atender a todos los patrones de variación que merecerían estudio, pero sí a los más claros, que identificamos a nivel del discurso: tanto en lo semántico-discursivo (en relación con la contraposición explícita de hablante/s y oyentes) como en lo sociodiscursivo (en relación con el grado de formación y con la revindicación de esta por parte de los hablantes y con la proyección de estas para construir roles discursivos).

No descartamos que investigaciones futuras puedan contribuir a restar especificidad al fenómeno cuzqueño, tanto en perspectiva sincrónica y diatópica (v. \$5.1) como diacrónica (v. \$5.2). Por de pronto, sabemos que se registra en otras partes del Sur de Perú y que, además, en al menos algunas regiones de Argentina, Bolivia, Chile, Ecuador y Uruguay parecen conocer el fenómeno, pero no sabemos si en estas áreas aparece solo en casos muy aislados o si es de uso general, como en el Cuzco. 
La serie de ejemplos anunciada, que se añade a los de (1)-(2) más arriba, es la siguiente (los contextos de uso, que constituyen el aspecto más interesante, se presentan entre paréntesis):

(3) ¡Límpien(se) vuestros zapatos! (respuesta recurrente de nuestros informantes cuando se les pedía que formularan la idea de ordenar a sus hijos el que ellos mismos se limpiaran sus zapatos / DGM2019)

(4) ¡Vuestra tarea hagan! ¡Hagan vuestra tarea! (la primera variante - con el orden de palabras "más andino"- la registramos en una informante de Ollantaytambo, 32 años, cuando se le pidió formular la idea de decir a sus dos hijas - presentes en el momento de la enunciación- que debían hacer ya la tarea de esa tarde; los demás informantes llegaron generalmente a la segunda variante, la cual, cuando finalmente la incluimos en nuestro cuestionario, pasó a ser considerada por muchos como un ejemplo típico para reflejar la interacción entre maestro y alumnos en la escuela / DGM2019)

(5) Ustedes descansan en la chacra, toman vuestra chicha y trago sentados, pero las que cocinamos lo hacemos sin descansar en la casa, ustedes no tienen consideración (mujer de unos 60 años de Huambomayo, Cuzco, dirigiéndose a sus hijos varones; testimonio recogido en Palomino Valdivia y Ojeda Escalante 2016: 299)

(6) Yo solo les voy a decir...este... disfruten vuestro día, vuestra salida... y abran los ojos, ¿no? (A.C., 40 años, cuzqueño, bohemio, un tanto ebrio en el momento final de la conversación, después de pedirle que nos diera algún consejo para la vida / DGM2019)

(7) ¿Ya se van a vuestros países? (M.A., 19 años, recepcionista de hotel en Cuzco / DGM2019)

(8) Bueno, agradecer a ustedes vuestra presencia y agradecer a los regidores por la prestancia a poder lograr esta ordenanza (jefa de la división de edificaciones de la municipalidad provincial de Cuzco al final de su turno de exposición en una rueda de prensa para la presentación pública de la ordenanza municipal 025-2019 sobre edificaciones sostenibles, a fecha de 5.12.2019 / DGM2019)

(9) Sin otro particular, y con la seguridad de vuestra comprensión y deseándoles mucha fortaleza espiritual en el acrecentamiento de nuestra Fe, pidiendo a la Santísima Trinidad y la Virgen del Carmen por vuestra salud y vida. Les bendice en Cristo y María, RDA, Arzobispo del Cuzco (carta del Arzobispo del Cuzco "a los hermanos(as), 
fieles y devotos de Nuestra Madre la Santísima Virgen del Carmen de Paucartambo", Cuzco, junio de 2020)

(10) ¿Qué artistas admiran o influyen en vuestra obra? (entrevista realizada a Heber Huamán y su hijo Pachacutec, escultores y artesanos herreros cuzqueños, para la revista Cuscopólita 5/16, abril 2015).

(11) a. El trabajo de investigación que ustedes están realizando, a ver, ¿qué podemos aportar para la vivencia donde nuestra población peruana pudiera encontrar muy buena comunicación? ¿Cuál es vuestro aporte, a ver?

b. Antes de poder despedirnos, Philipps, al igual que Miguelito, con el agradecimiento... ojalá no sea la primera...ojalá otra vez cuando vengan y estén por el Perú, un saltito para que visiten aquí, porque este es vuestro segundo hogar, con confianza, para poder hablar, dialogar y decir los problemas que de repente ustedes han tropezado al visitar la ciudad imperial del Cuzco (ambos ejemplos en boca de S.A., 58 años, cuzqueño, locutor de Radio La Hora —donde fuimos entrevistados en un programa especial-, extendiéndonos una nueva invitación para visitar su programa en una próxima ocasión. 5.12.2019 / DGM2019)

(12) Luego esperamos recibir vuestras valiosas opiniones y sugerencias al teléfono 260575 (locutor del programa cultural dominical en la Radio Metropolitana Cuzco, invitando a todos los oyentes a participar, 1.12.2019)

En el resto del artículo retomaremos a menudo estos ejemplos para la caracterización del vuestro cuzqueño desde un punto de vista estructural y variacional.

\section{Características generales del uso cuzqueño de vuestro}

\subsection{Significado exclusivamente plural}

Ninguno de los entrevistados aceptó usos de vuestro con referencia singular. En palabras de los informantes, solo es válido "cuando estamos hablando en grupo" o cuando "significa varios". Esta es una diferencia fundamental del español cuzqueño con respecto al de otras regiones donde se ha indicado el uso marginal de vuestro también en singular —además de plural — en contextos formales 
(integrado, por tanto, en el paradigma de usted): v. Wagner (1996/1997) para Chile y Bertolotti (2007) para Uruguay. Reseñando, por cierto, este último estudio y otros sobre tratamientos en aquel país, Steffen (2010: 460) terminaba su trabajo preguntándose si tal vez futuras investigaciones no revelarían una mayor supervivencia de vuestro en otras áreas americanas. Los datos que presentamos implican, evidentemente, una respuesta afirmativa, si bien la referencia exclusivamente plural del uso cuzqueño es un hecho importante.

Por lo que respecta a Perú, según el testimonio de Hildebrandt (2012: 388; v. \$3.2), también se llega a registrar vuestro singular como posible sustituto de $s u$ (en el paradigma de usted) en documentos parlamentarios. Por lo tanto, este uso quedaría restringido sobre todo a esta tradición discursiva, que nace en un contexto político eminentemente limeño; incluso, aunque pudiera registrarse en algunas tradiciones más, estas no parecen alcanzar el nivel provincial del Cuzco y, en ningún caso, el habla de nuestros informantes cuzqueños, que, como se dijo, rechazan el significado singular de vuestro.

Además, algunos informantes ni siquiera aceptaban las variantes con $s u$ (es el tercer grupo de hablantes al que nos referimos al principio, aquellos que aparentemente solo aceptan vuestro como posesivo de 2P.PL). En estos casos, solían asociar automáticamente estas últimas con la referencia singular (paradigma de usted) o, secundariamente, con la 3P.PL (por ejemplo, rechazaron el uso de la oración ¿Cómo les va su trabajo? presentada como variante de ¿Cómo les va vuestro trabajo?). Otros informantes aceptaban las dos variantes, aunque indicaban que el significado plural es más claro en la oración con vuestro (lo que enlaza con la idea tradicional de su uso desambiguador, sobre todo en el sentido de la ambigüedad referencial singular o plural del alocutario).

Cabe aclarar que el significado plural de vnestro como posesivo de ustedes no impide que la misma forma pueda aparecer como parte de honoríficos, es decir, de aquellos tratamientos, a menudo singulares, consistentes en el determinante vuestro y un sustantivo 
abstracto, del tipo de Vuestra Excelencia/Señoría/etc., asociados a determinados cargos en situaciones oficiales. Este tipo de fórmulas se constituyeron en la Temprana Edad Moderna ${ }^{4}$, estando muy presentes durante toda la etapa colonial, y pudieron adaptarse a nuevos significados durante la constitución de las diferentes repúblicas americanas (por ejemplo, en discursos parlamentarios: Vázquez Laslop 2012: 136) y a veces sobrevivir hasta la época actual ${ }^{5}$. Un tratamiento algo especial dentro de este grupo es el uso alocutivo de vuestra persona, el cual es posible en el Perú actualmente (aunque no nos consta bibliografía sobre el tema):

(13) Por favor, envíenos un número de teléfono para poder comunicarnos con vuestra persona y poder darle un mejor alcance de la iniciativa (e-mail con fecha de 20.1.2020, surgido en contexto académico, remitido a nuestro colega y amigo Luis Andrade, profesor de la PUCP, a quien agradecemos facilitarnos el ejemplo)

No podemos descartar que este tipo de fórmulas de tratamiento pudieran haber contribuido, en alguna etapa histórica anterior, a mantener viva, en general, la forma vuestro, a hacerla más accesible para permitir una apropiación/refuncionalización posterior como auténtico posesivo/relacional referido al oyente (y, en este caso, quizá, tanto con referencia plural como singular, dado que

4 El concepto de Temprana Edad Moderna (que utilizamos más como traducción del alemán Frübe Neuzeit que del inglés Early modern period) incluye, al menos, los siglos XVI y XVII, si bien algunos historiadores extienden el período al siglo XVIII y, en cualquier caso, el proceso de transición hacia la etapa siguiente de la Modernidad es extenso (Zwierlein 2009: 22). A menudo, se han señalado hitos que marcarían en cada región europea el inicio de una nueva etapa en la historia de Occidente, unos de magnitud evidente (como el fin de la Guerra de los 30 años, en el caso alemán), otros de carácter más simbólico (el incendio de Londres de 1666, que dio lugar a la aparición de nuevas formas de aseguración y de reformas del sistema financiero, en el caso inglés); en el ámbito hispánico, las reformas borbónicas dieron paso definitivamente a una nueva etapa - también en lo que respecta a la diplomática indiana (Real Díaz 1970: 17)—, aunque, en realidad, se llegara a esta paulatinamente desde cambios anteriores en lo político, social, institucional, etc.

5 De hecho, ni siquiera descartamos que pudieran formarse otras formas nuevas a partir del mismo esquema formal, la cual tendría entonces una cierta productividad, si bien no necesariamente idiomática, al menos sí dentro de ciertos ámbitos discursivos. 
los sintagmas “vuestro $+\mathrm{N}$ ” con función alocutiva podían ser singulares o plurales). Sin embargo, es evidente que unos usos y otros se presentan como fenómenos claramente diferenciados, al menos en la actualidad (de hecho, pensamos que hay otras explicaciones históricas más claras para dar cuenta del origen/mantenimiento del vuestro plural cuzqueño: v. \$5.2).

\subsection{Integrado en el paradigma de ustedes}

El uso de vnestro que estudiamos forma parte del paradigma de ustedes. Este es, pues, el resultado estable de la "fusión de paradigmas" (Fontanella de Weinberg 1992b) de ustedes y vosotros en el español de la región. Las otras formas de vosotros apenas tienen presencia en el Cuzco: de hecho, esperaríamos que la frecuencia fuera aquí aún menor que en Lima, dado que el paradigma-u/v cuzqueño parece asumir algunas de las funciones del paradigma-v (Caravedo 2019), además de otras funciones específicas. En una conversación con dos cuzqueñas de mediana edad, una informante no rechazaba del todo el posible uso de vosotros (y de su paradigma completo), en tanto que le parecía una forma que aún se podía enseñar en las escuelas, mientras que la otra respondió con claridad: “¿vosotros? pero suena raro, hasta para mí suena raro; pero el vuestro es normal, muy normal".

Este testimonio ( $y$, en realidad, cualquier experiencia con hablantes cuzqueños en su región de origen) basta para observar que el uso de vuestro inserto en el paradigma de ustedes es un fenómeno regular en Cuzco, distinto del uso muy restringido de vosotros y su paradigma. Esto no impide, por cierto, que pueda existir una relación histórica entre ambos fenómenos, es decir, que el primer uso derive en parte del segundo, aunque no sea este el aspecto determinante que explique el uso de vuestro (v. \$5.2). De hecho, dado que se tiende a asumir que la extensión de ustedes en América no data en ningún caso de antes del siglo XVIII, debió existir una época en que el paradigma de vosotros fuera usado con todas sus formas, antes de ser reemplazado por el de ustedes (si bien el reemplazo no 
fue total). Y es precisamente este paradigma completo de vosotros, según el uso antiguo colonial, adaptado y circunscrito después a ciertos dominios formales en el siglo XIX (Bertolotti 2007, 2020; Caravedo 2019), el que existe aún en la actualidad. En un trabajo reciente, Caravedo (2019: 31) define este último uso de la siguiente manera:

En el Perú, por ejemplo, ese mismo significante [=vosotros, y su paradigma] forma parte del conocimiento de los hablantes con un significado opuesto al peninsular: tiene un valor deferencial, referido a interlocutores virtuales en situaciones comunicativas de alto grado de formalidad, como discursos solemnes orales o, en la escritura, invitaciones formales, a diferencia del uso castellano norteño y central. Es decir, vosotros no es el plural de tú en la cognición de los hablantes de esta zona. Aunque ustedes es el pronombre general para referirse a más de un interlocutor (en sentido inclusivo o exclusivo), la aparición esporádica pero regular de vosotros revela que este pronombre no ha desaparecido totalmente del paradigma de los hablantes, de modo que se utiliza en contextos definidos.

Caravedo (2019), que no tiene en mente específicamente al Cuzco en este trabajo, no se refiere aquí al paradigma-u/v. Más interesante aún —en tanto que recoge, aun de forma poco sistemática y desde una ideología lingüística muy concreta, los problemas que nos conciernen- es el siguiente testimonio de Martha Hildebrandt (autora de reconocido prestigio intelectual en la vida pública cuya actividad académica ha estado ligada a la divulgación de una norma prescriptiva). Destacamos en negrita los fragmentos que se refieren concretamente al fenómeno estudiado (el resto de la cita comenta - $\mathrm{O}$, cuando menos, tiene en cuenta - el uso de vuestro singular: v. \$3.1):

Suyo (con sus variaciones de género y número) y $s u$ (con su plural) son, pues, posesivos ambiguos. Y, tal vez para evitar la ambigüedad, se cae en el error de construir frases en que se mezclan formas correspondientes a ustedes con otras correspondientes a vosotros. 
Oradores y políticos (incluidos algunos congresistas) caen a veces en ese error, que puede constatarse hasta en textos y fórmulas oficiales del más alto nivel. En documentos parlamentarios, por ejemplo, se leen frases como "Ha llegado a vuestra Comisión...", pero no se trata al destinatario de vos, sino de usted. En este caso, "vuestra Comisión” puede ser correctamente sustituida por "su Comisión”, o “esta Comisión” si el su no satisface por ambiguo.

Hemos oído a locutores de televisión despedirse con la fórmula "les agradecemos por habernos dejado entrar en vuestros hogares", frase que resulta, al mismo tiempo, artificiosa e incorrecta. Lo correcto y natural es "les agradecemos por habernos dejado entrar en sus hogares”. La ambigüedad es inherente al lenguaje y el contexto se encarga, generalmente, de aclararla.

En Madrid podría decirse, con naturalidad, “os agradecemos por habernos dejado entrar en vuestros hogares”. Pero en América vosotros, vuestro y os no son usuales en la lengua culta familiar, y tienen por eso un cargado matiz de artificio y solemnidad. Por qué, entonces, arriesgarse a usar la forma vuestros en casos en que va tan mal unida a les?

En el habla culta de la América hispánica no hay, pues, obligación de decir vos, ni vosotros, ni vuestro, ni os. Pero, si se opta por usar el posesivo vuestro, no queda más remedio que emplear también, obligatoriamente, los correspondientes pronombres personales vos, vosotros y os (Hildebrandt 2012: 388-389).

La autora no concreta la procedencia de los oradores y locutores que emplean las frases como Les agradecemos habernos dejado entrar en vuestros hogares, la cual podría escucharse cotidianamente en emisoras de radio cuzqueñas (v. ej. (11)-(12) arriba y Dankel y Gutiérrez Maté 2020: 321). Si su ejemplo no proviniera de un medio cuzqueño, sería indicio de que el paradigma-u/v también existe en otras regiones. Sea como fuere, la autora destaca varios hechos estructurales y sociolingüísticos: primero, que el paradigma-u/v tiene cierta vigencia de uso; segundo, que no hay otros resultados de la hibridación de los paradigmas de vosotros y ustedes (del tipo de, por ejemplo, *Os agradecemos habernos dejado entrar en sus 
hogares); tercero, que el paradigma-u/v sería quizá consecuencia de la ambigüedad referencial del posesivo de tercera persona (su); cuarto, que vosotros existe en el "habla culta" peruana, aunque no haya obligación de usarlo (bastaría con el ya culto ustedes) y ni siquiera sea válido (o, al menos, no "sea usual”) en la "lengua culta familiar", por traer demasiado "artificio y solemnidad"; quinto, que, si acaso se usaran formas de vosotros, el paradigma-u/v debería evitarse en cualquier caso.

El uso del paradigma-u/v es, así, condenado vehementemente por la autora (tanto en esta obra como en Hildebrandt 2011: s.v. vuestro); sin embargo, ya que parece conceder un papel decisivo al "habla culta", hay que observar una incongruencia en su argumentación, dado que los hablantes cuzqueños más cultos emplean también el paradigma-u/v y que tanto estos como otra gente más humilde de la región tienden a asociar su uso con la buena educación (v. \$4.3). Al parecer, en un caso como el descrito aquí, falta aún la suficiente reflexión sobre el estatus de algunos fenómenos como rasgos dialectales terciarios (en el sentido de Coseriu 1982) y sobre la constitución de estándares regionales dentro de un mismo territorio nacional, si bien sea cierto que, por lo que respecta al fenómeno estudiado, la norma limeña podría ejercer cierta presión sobre la cuzqueña.

Entendemos, no obstante, los motivos que llevan a la animadversión de muchos hacia aquellos fenómenos que, de manera más perceptible, resultan de la hibridación de soluciones lingüísticas anteriormente independientes. Aquí, el paradigma-u/v, que combina dos paradigmas que existen o habían existido antes de manera autónoma, se percibe, antes que nada, como una "mezcla”, la cual es, por definición, incompatible con el "purismo” lingüístico. De hecho, en el caso de los paradigmas mixtos cabe recordar un ejemplo célebre en la historiografía de las variedades hispanoamericanas: el rechazo de Cuervo del paradigma de 2P.SG del tipo vos-te-tuyo en sus Apuntaciones críticas sobre el lenguaje bogotano (1867-1871). Cuervo, quien ya comenzaba señalando que el uso de vos en vez de tú es "tan común como repugnante", añadía que "si el uso que 
hemos dicho se hace de vos fuese constante, sería soportable; pero nadie dice os [...] sino que en su lugar se usa te, de lo cual resulta un menjurje que encalabrina los sesos” $\left(\$ 305,154-155\right.$ de la $2^{\mathrm{a}}$ ed. de 1876).

3.3. Uso idiomático (aunque más frecuente en ciertas tradiciones discursivas)

De nuestros datos se deduce que todo hablante cuzqueño (al menos, todo hablante con cierta formación) puede llegar a emplear el vuestro de 2P.PL en determinadas circunstancias (más especiales para unos hablantes que para otros). Esto incluye a los jóvenes que aparentan utilizarlo menos a menudo y que se muestran más reacios a reconocer su uso. Así, por ejemplo, la oración de (7) fue pronunciada por un informante al que habíamos entrevistado dos días antes y que nos había asegurado que él nunca utilizaría vuestro $0^{6}$.

El empleo de vuestro como alternativa a su responde a ciertas estrategias comunicativas (vid $\$ 4$ ), lo que no impide que sea casi obligatorio para la elocución de ciertos actos de habla en determinadas situaciones. Decimos "casi obligatorio" porque, seguramente, no existan usos de vuestro completamente convencionalizados (siempre hay, en nuestra opinión, algún remanente estratégicopersuasivo): lo formulaico y lo estratégico son solo polos de un continuo. En todo caso, tenemos usos eminentemente formulaicos cuando, por ejemplo, vuestro forma parte regularmente de la expresión del agradecimiento al grupo de asistentes al final de asambleas (gracias por vuestra asistencia), de la manifestación del deseo de complacencia al público/espectador (espero que sea/haya sido de vuestro agrado), de la petición de permiso en contexto oficial (con

\footnotetext{
6 Quepa aclarar que si utilizó vuestro no fue por afán de complacencia o de bromear con nosotros: dado que en la entrevista anterior habíamos hablado de muchos temas, por lo general mucho más memorables que el uso o no de una determinada forma lingüística, creemos que ni siquiera tenía presentes los problemas en torno a vuestro cuando formuló la oración de (7). De hecho, cuando le llamamos la atención sobre el hecho de que acababa de usar algo de lo que poco antes había abjurado, no notamos ninguna señal de complicidad para con nosotros sino, al contrario, un sentimiento sincero de vergüenza.
} 
vuestro permiso) y de otros muchos tipos de peticiones formales, incluyendo la petición de atención para dar inicio a un aviso público (vuestra atención, por favor). Por otra parte, más allá de los actos de habla recién indicados, su uso sería esperable —aunque no esté del todo convencionalizado- en textos de altos cargos eclesiásticos a comunidades de fieles (ejemplo 9), en las órdenes o interpelaciones de maestros a alumnos (ejemplo 4) y en los discursos de alcaldes y otros altos cargos políticos (ejemplo 2; Dankel y Gutiérrez Maté 2020: 322).

Se requiere aún mucha investigación para poder definir más concretamente las tradiciones discursivas en las que vuestro se ha convencionalizado, pero el planteamiento general nos parece incuestionable: existen, por una parte, usos de vuestro ligados a tradiciones discursivas específicas o incluso completamente formulaicos y, por otra, usos idiomáticos dependientes de las estrategias de comunicación de los hablantes en un momento dado. Nos estamos basando aquí en la distinción de Koch (1997) entre el dominio de las tradiciones discursivas, con sus "reglas discursivas", y el dominio de la lengua histórica particular, con sus "reglas idiomáticas”, dentro del nivel histórico-idiomático del lenguaje.

Poner límites precisos entre lo tradicional-discursivo y lo idiomático es tarea difícil que requiere, en el caso ideal, el complemento de una metodología cuantitativa que aún no hemos podido aplicar. Basta indicar que seguramente el uso invariable de vuestro parece haberse constituido, entonces, como parte de las reglas de ciertas tradiciones discursivas, mientras que la regla idiomática en la variedad cuzqueña consistiría, en principio, en la posible alternancia de dos formas de posesivo de 2P.PL (vuestro / su) en función de factores que definiremos más adelante ( $\$ \int 4$ 4.1-4.2). Por otra parte, huelga decir que para los pocos hablantes que no aceptan sino vuestro como posesivo de 2P.PL (aquellos que interpretaban su para la alocución singular: v. \$2.1), esta forma es también plenamente idiomática.

Cabe advertir que una de las tradiciones discursivas en las que esperábamos ver más a menudo vuestro resultaron no incluir ejem- 
plos: nos referimos a las fórmulas de invitación al final de las tarjetas de boda, cumpleaños, etc., que, como han estudiado Morgan y Schwenter (2016) para el caso de Chile, presentan a veces vuestro. Sin embargo, ello no implica necesariamente una preferencia real de su sobre vuestro; de hecho, después de leer muchas tarjetas y entrevistar a los encargados de varias librerías, llegamos a la conclusión de que en el Cuzco, aunque la inclusión de una referencia plural es posible, estos textos se construyen teniendo en cuenta generalmente a un destinatario singular (Le agradecemos por su gentil asistencia; Después de la ceremonia sírvase pasar a...; etc.).

Las consideraciones anteriores se refieren al posible uso de vuestro como parte del paradigma-u/v. En realidad, la situación se complica en la medida en que también el paradigma-v puede llegar a aparecer en el Cuzco, por marginal que sea, estando su uso ligado a tradiciones discursivas muy específicas. De hecho, solo lo hemos encontrado - y solo ocasionalmente- en algunas partes de las celebraciones litúrgicas: concretamente, en las lecturas en boca del cura, ya que la hoja que circula en la iglesia con las lecturas, que se envía desde Lima (con textos aprobados por la Conferencia Episcopal Peruana), incluye solo formas del paradigma de ustedes (incluyendo el posesivo $s u)^{7}$.

\section{Hacia una comprensión de las alternancias entre vuestro y su}

Según lo expuesto en los capítulos anteriores, cuando decimos que el uso de vuestro entra a formar parte de la variedad cuzqueña estamos sosteniendo también que, por lo general, no desplaza al panamericano $s u$, sino que constituye, junto con este último, una variable lingüística ("formas del posesivo de 2P.PL: vuestro vs. su"). Hemos reconocido también que, aunque, como tal variable lingüística, merecería ser estudiada con una metodología variacionista (entién-

\footnotetext{
7 Durante nuestra estancia asistimos a varias misas en la Catedral y en la Basílica Menor de la Merced, en la que ocasionalmente escuchamos las formas de vosotros. La hoja con el contenido de la celebración es una publicación periódica con el título de El domingo día del Señor, a cargo de la editorial San Pablo, con sede en Miraflores (Lima).
} 
dase, un análisis estadístico-inferencial), aún no hemos podido emprender tal análisis, que es, por ahora, cualitativo. Sin embargo, advertimos ya algunas tendencias con respecto al uso contrastivo de vuestro en el discurso $(\$ 4.1)$, presentamos algunas bases semánticas en las que puede apoyarse tal contraste $(\mathbb{S} 4.2)$ y trazamos el perfil sociolingüístico prototípico del hablante usuario de vuestro, así como las circunstancias donde más fácilmente lo emplearía (\$4.3).

\subsection{El valor en el discurso: el contraste}

Si hubiera que definir un valor de vuestro más habitual entre los hablantes cuzqueños y lo suficiente abstracto como para poder incluir una amplia gama de usos derivados, este sería el de explicitar un contraste o contraposición entre el hablante (o los hablantes) y los oyentes: concretamente, entre las ideas/actitudes y/o entre la posición o grupo social de uno(s) y otros. Se trata, pues, de un contraste que tiene una base psicosocial y que funciona a nivel discursivo (siendo los roles psicosociales de los participantes constantemente actualizados en el desarrollo del discurso). Así, por ejemplo, es clara la distinción de roles de la madre y los hijos de los ejemplos (3)-(5) —estando la primera en la posición de dar órdenes (en (3) y (4)) o de hacer reproches (en (5)) a los segundos-, del mismo modo que lo es aquella que media entre la alcaldesa y los ciudadanos en (2), o entre el locutor de radio y sus fieles oyentes en (12).

En principio, el hablante que emplea vuestro se excluye a sí mismo de las acciones o estados que conciernen a los oyentes, lo que generalmente conlleva una distancia psicológica con respecto a estos. El contraste está siempre presente de un modo u otro: por ejemplo, en (5), al decir que "ustedes [...] toman vuestra chicha y trago sentados", se está resaltando también el hecho de que la hablante no lo hace. De hecho, el contraste no es solo entre los hijos y su madre, sino entre los chicos que no colaboran y las mujeres que trabajan siempre ("las que cocinamos [...] sin descansar"). A raíz de este ejemplo, y de (11.a), donde la 1P.PL está explícita (nuestra población peruana), cabe advertir que la contraposición 
de roles es más evidente aún cuando el hablante representa a una primera persona plural (v. más ejemplos en Dankel y Gutiérrez Maté 2020: 320-325). Esta especie de 1P.PL exclusiva - manifestada, sin embargo, como una 2P.PL contrastiva- no necesita estar formulada explícitamente por medio del paradigma gramatical de nosotros: a menudo, incluso cuando el hablante utiliza la 1P.SG, esta puede estar representando el grupo al que el hablante pertenece. Por ejemplo, en (6), el bohemio cuzqueño había estado hablando de aquellos que, siendo descendientes de incas, son hoy marginados sociales, y era de alguna manera en nombre de todos ellos en los que da consejos a los dos extranjeros interesados por la cultura cuzqueña (probablemente, en su construcción de la imagen del grupo en el que nos incluía no faltaron características como la ingenuidad, la búsqueda de exotismo, la ambición profesional o la riqueza). A su vez, incluso el ejemplo de (1) podría leerse en clave no formulaica sino estratégica: el guía turístico nos da explícitamente la bienvenida a su pueblo, a su país, por lo que su deseo de que la experiencia haya sido de nuestro agrado es, en realidad, el deseo de toda la gente de Ollantaytambo y de todos los peruanos, a los que se presenta así como una comunidad hospitalaria para con nosotros, extranjeros. Algo similar podría decirse de (8) —otro ejemplo a mitad de camino entre lo formulaico y lo estratégico-, donde la hablante finalmente muestra su gratitud no solo personal sino, indirectamente, en nombre de su división (en realidad, además no hay solo agradecimiento sino esperanza de que su mensaje haya calado entre los asistentes al acto).

La contraposición entre hablantes y oyentes se suele utilizar -al menos en una parte significativa de los ejemplos- no tanto para marcar simplemente las diferencias de los roles de unos y otros como para, a partir de estas, destacar una actuación conjunta, una unión de intereses o una sintonía en la visión del mundo. Esta es, seguramente, la estrategia retórica más habitual que implica el uso del vuestro. Precisamente, esta complicidad es la que busca la alcaldesa en (2) ("vuestro respaldo") o el arzobispo en (9) ("vuestra comprensión"); y difícilmente la comunión entre hablante y oyentes 
puede ser mayor que cuando, como en el ejemplo (11.b) ("vuestro segundo hogar"), se crea el topos discursivo del hogar familiar en el que conviven los cuzqueños, representados por el locutor de radio, y - previa invitación de los primeros - los investigadores extranjeros que se interesan por la cultura cuzqueña.

Por lo que respecta a (3)-(5), es posible que no haya "estrategia retórica” sino un acto más convencionalizado, pero, en todo caso, nos parece evidente que los hablantes tienen la expectativa de que la reacción de los oyentes (la perlocución del acto de habla) resuelva en cada caso los conflictos que habían desencadenado los correspondientes actos comunicativos: se cuenta, por tanto, con que los hijos terminarán limpiándose los zapatos tras escuchar (3), haciendo los deberes tras escuchar (4) y ayudando en las tareas de la casa tras escuchar (5).

4.2. El valor semántico-referencial y pragmático: referencia grupal específica, posible significado distributivo, ilocución directa

El hecho de que el contraste entre hablantes y oyentes opere en el nivel del discurso, no impide que, en ocasiones, se reconozca ya en el nivel lógico-proposicional, por lo que, en algunos casos al menos, se puede dar cuenta de él utilizando categorías lingüísticas tradicionales provenientes de la semántica (en función de los distintos tipos de referencia plural y de cómo estos determinan la predicación) y de la estructura informativa (sobre todo en función con la dicotomía fondo-foco). Generalmente, además, la fuerza ilocutiva de las proposiciones semánticas (esto es, el acto de habla) moldea la progresión del discurso, por lo que también algunas categorías pragmalingüísticas nos pueden ayudar, a cierto nivel, a comprender mejor el uso de vuestro. Este apartado se dedica, por tanto, a algunas de las bases semánticas y pragmáticas del contraste que hemos definido antes al nivel del discurso.

A nivel semántico, sería útil establecer subcategorías dentro de la pluralidad. En primer lugar, observamos que algunos hablantes prefieren usar vuestro cuando se dirigen a grupos, pero lo rechazan para 
el tratamiento a dos personas. Así, preguntábamos a dependientes de tiendas, recepcionistas de hoteles, etc. qué palabras utilizarían si, debiendo cerrar durante unas horas, tuvieran que salir a calmar a la multitud que aguarda para entrar; en estos casos, cuando había formas de posesivo implicadas, consistían generalmente en la forma vnestro (del tipo gracias por vnestra paciencia). A nuestra pregunta de por qué utilizaría vuestro y no $s u$ en esos casos, un informante nos respondió "si manejo un grupo amplio, la utilizaría [...] creo que es para tratar a un grupo mayor". Evidentemente, abundan los contraejemplos (sin ir más lejos, cada vez que los dos entrevistadores recibían el tratamiento de vuestro), pero no descartamos que algunos hablantes puedan introducir esta distinción semántica, sobre todo teniendo en cuenta que la contraposición de grupos nos parece el criterio definidor básico del uso de vuestro.

En segundo lugar, nos parece imposible el uso de vuestro para un destinatario plural genérico. La contraposición entre hablantes y oyentes tiene lugar con la actualización de las dinámicas interactivas, por lo que no esperamos la presencia de vuestro en discursos cuya autoría queda difuminada en un colectivo inespecífico o dirigidos a destinatarios potenciales (por ejemplo, en documentos oficiales que caen en la tradición del To whom it may concern/"A los efectos que proceda"). Es obvio que el tratamiento a un grupo, aunque no implica especificar la extensión (esto es, el número de ejemplares: aquí, el número de alocutarios), sí exige una definición de las características generales del grupo para su posible clasificación como tal (intensión semántica), la cual se consigue cuando el hablante tiene algún conocimiento o, cuando menos, algunas expectativas sobre las circunstancias e intereses del grupo en relación con el bic et nunc de la enunciación. Tal vez por ello, y porque el propio emisor es inespecífico (o una entidad abstracta), no esperaríamos nunca la aparición de vuestro en casos como los siguientes:

(14) Señores pasajeros, sírvanse abordar $s u$ tren por las puertas de embarque señaladas en $s u$ boleto (anuncio por megafonía en la estación de tren de Ollantaytambo; julio de 2016) 
(15) Agradeciendo su atención y sin otro particular, nos despedimos de ustedes. La administración (comunicado a la puerta de la Catedral del Cuzco, dirigido a las agencias de viaje, sobre la obligatoriedad de presentación de ticket de ingreso en mano; diciembre de 2019)

Los dos casos siguientes son distintos en el sentido de que los hablantes no solo reaccionan a las dinámicas interactivas, sino que también las construyen. Aunque haya una cierta inespecificidad del destinatario (posibles visitantes virtuales, pueblos de África e India en general), el emisor determina implícitamente una serie de cualidades básicas de los destinatarios conforme a su conocimiento del mundo y a sus expectativas o intereses; en otras palabras, se construye una identidad grupal de los destinatarios (reivindicación de identidad que se explicita incluso al principio de (17)), con respecto a la cual se posiciona el hablante y el grupo al que pertenece (los responsables del museo se posicionan como agentes hospitalarios y vehiculadores del patrimonio cultural para los visitantes; los indígenas peruanos se posicionan como "hermanos" con respecto a los africanos e hindúes). Todo ello lleva al uso de vuestro:

(16) M: A través de su programa patrimonio, acompáñennos a recorrer este interesante museo en explicación de su administrador Juan Carlos Becerra. J: Los invitamos a pasar a nuestros diferentes salones, para vuestro[sic] mayor apreciación y para que ustedes también, al ver y al ex... al a:h poder experimentar desde vuestros hogares este gran museo (bienvenida del administrador de un museo en la región de Cuzco en un video promocional del Ministerio de Cultura, enero de 2017).

(17) Espero que de igual manera ustedes conserven vuestra identidad. [...] Hermanos de África, hermanos de India, si nos unimos de una sola fuerza, vamos a tener este maíz, como lo tenemos aquí en el Perú, sus maíces como tienen ustedes por allá. (comunicación por video de un indígena de la región de Cuzco que es miembro de un movimiento de protección de la cultura ancestral y activista contra el uso de semillas industriales, agosto de 2018).

En tercer lugar, el empleo de vuestro sirve para destacar vínculos individuales entre el evento y el grupo de destinatarios, una lectura 
que podemos denominar "distributiva", la cual, de hecho, se anticipaba también en los ejemplos anteriores: en (16) cada destinatario visitará virtualmente desde sus respectivas casas, del mismo modo que en (17) cada pueblo conservará su propia identidad. Incluso, varios informantes incluso comentaron explícitamente esta lectura, sobre todo a partir de ejemplos como los de (3)-(4): explicaron, por ejemplo, que al decir Hagan vnestra tarea se estaría enfatizando 'cada uno, la suya'. En efecto, esta lectura es clara en muchos otros ejemplos vistos a lo largo del trabajo ((3), (4), (5), (7), (14), etc.), pero no encaja con (6) (donde vuestra salida es una salida en grupo), ni con (10) (donde vuestra obra es la obra conjunta de los dos escultores), ni con (11.a) (donde vuestro aporte implica el aporte conjunto de los dos investigadores). En este sentido, no pensamos que el hecho de que cada destinatario sea participante individual del evento ocasione necesariamente la aparición de vuestro; más bien parece que este tipo de relación se presenta frecuentemente en casos en que la suma de todas las participaciones individuales de los oyentes se contrapone, a su vez, a la relación del hablante con respecto al mismo evento, lo que redunda, a nivel discursivo, en el contraste que hemos venido explicando ( $\$ 4.1)$.

Además, elaborando su explicación de la lectura distributiva, otra informante añadió finalmente el uso del cuantificador universal para parafrasear vuestro: concretamente, ¿Han hecho vuestra tarea? equivaldría a ‘ ¿Todos han hecho la tarea?’ En otras palabras, vuestro tiene también un valor cuantificador: ... haya sido de vuestro agrado (='del agrado de todos y cada uno de ustedes'), ... agradecerles por vuestro respaldo (='el respaldo de todos y cada uno de ustedes'), etc. En estos casos, la lectura distributiva depende del establecimiento de un valor grupal vehiculado por el empleo de vuestro, frente a $s u$, que también vale para dirigirse a una pluralidad no especificada como tal grupo, sino como una mera colección de individuos.

Por otra parte, en un plano informativo-estructural, observamos que el uso de vuestro puede ir ligado a la categoría de foco contrastivo (vnestro X = 'el X de ustedes, no el mío/nuestro') (v. Lambrecht 1994, y Hartmann y Zimmermann 2007 para una definición y tipo- 
logía de focos): disfruten [...] vuestra salida (ej. 6) = 'disfruten la salida que ustedes están haciendo, no yo (ni los que estamos aquí)’, ¿cuál es vuestro aporte, a ver? (ej. 11.a) = ‘cuál es el aporte de ustedes, no el nuestro' (en realidad: ‘ ¿cuál es el aporte de ustedes para con nosotros?'), esperamos recibir vuestras valiosas opiniones (ej. 12) = 'esperamos las opiniones de ustedes, no de los que estamos aquí (que ya hemos opinado durante todo el programa)', etc. Este contraste entre poseedores (entendiendo la relación entre poseedor y poseído, en realidad, como una más abstracta, entre relacionante y relacionado) tiene a menudo reflejo directo en la progresión del discurso, por lo que es uno de los contextos típicos del uso estratégico-contrastivo de vuestro.

En otro orden de cosas, es obvio que algunos tipos de actos de habla (por ejemplo, actos directivos de mandato) plantean por naturaleza una contraposición entre los oyentes y el hablante (que no participa directamente de la perlocución del acto y está en la posición social y/o moral de imponerse sobre el oyente, si las condiciones de felicidad son las esperadas), pero esta es completamente circunstancial en otros (sobre todo, en actos asertivos). Es en este sentido en el que podemos identificar también algunas tendencias a nivel pragmático que contribuyen al uso de vuestro. Así mismo, pensamos que la formulación más o menos explícita del acto ilocutivo (esto es, la presencia/ausencia del verbo performativo) tiene un reflejo de la selección o no de las formas con mayor "peso pragmático” (Davidson 1996). Observemos los siguientes ejemplos:

(18) Quiero agradecerles por vuestro respaldo. No los defraudaré. Con el mismo temple que pido su apoyo, también les manifiesto que seremos todos [...] guardianes del patrimonio cultural y humano (alcaldesa de Cuzco, mensaje de Fiestas Patrias, 28.7.2020)

(19) a. Vuestros pasaportes, por favor (recepcionista de hotel, en la alocución directa a clientes / DGM2019)

b. Soy M., el recepcionista de turno, bienvenidos al Cuzco, por favor si me podrían facilitar sus pasaportes, para poder hacer el check-in (el mismo recepcionista, imaginando, a petición nuestra, su saludo de bienvenida y la petición de datos a nuevos clientes / DGM2019) 
En (18), que repite (2), se registra vuestro para llevar a cabo el acto de agradecimiento inicial (vuestro respaldo), el cual supone en realidad un acto indirecto de petición (la estrategia es la de adelantarse a dar las gracias por algo que aún no ha obtenido y que antes debe pedir); poco después, al admitir que se trata de una petición pero presentarla inserta en un acto de habla comisivo, por medio del cual promete el éxito conjunto, se registra su (pido su apoyo). En (19), por su parte, tenemos un par de ejemplos en boca del mismo informante: en el primero, con vuestro, se lleva a cabo la ilocución de un acto de habla directivo-petitivo, mientras que en el segundo, con $s u$, la situación es artificial (le pedimos que imaginara cómo hablar) y además aparece una marca explícita de performatividad: concretamente, la construcción subordinativa de interrogativa indirecta, si bien el verbo performativo en sí está ausente ("por favor, [les pido/pregunto] si me podrían facilitar sus pasaportes”). De comprobarse esta tendencia, diríamos que, para ciertos tipos de actos ilocutivos, la forma más 'económica' es aquella con la que mejor combina vuestro; en otras palabras, las tensiones entre brevedad y claridad juegan un papel determinante: cuando el hablante explicita la ilocución del acto de habla (por medio del verbo performativo o algún recurso homologable, como en (19)), predomina la claridad sobre la brevedad; por contra, cuando la ilocución queda implícita, predomina la brevedad, pero entonces el hablante intenta ganar en claridad de alguna manera: para ello, recurre al empleo de formas semántica e informativamente marcadas que atraigan la atención del oyente, lo que es especialmente pertinente en la medida en que se introducen formas con las que se integra formalmente al propio oyente en el enunciado (tratamientos) y especialmente eficiente repetimos, para ciertos tipos de actos de habla- en la medida en que la forma seleccionada concretamente suele llevar aparejada una contraposición entre hablante y oyente. Además, de algún modo relacionado también con la claridad, observamos algunos ejemplos, donde las oraciones con vuestro parecen señalar el acto de habla principal de un segmento conversacional dado a cargo del hablante (colocándose generalmente al principio), como en el caso de (17) 
y (18), que tienen una estructura relativamente semejante: una vez establecida el acto directivo petitivo inicial (petición de apoyo - planteada como un acto de agradecimiento- en (18) y de conservación de la propia identidad — planteada como un acto expresivo desiderativo- en (17)), se pasa a un acto a caballo entre lo asertivo y lo comisivo donde se plantean los beneficios de una actuación conjunta. Para este último, la forma empleada en ambos casos es $s u$.

Es interesante anotar, por último, la valoración subjetiva de dos hablantes que atribuían a los enunciados con vuestro un cierto carácter de "apuro" (20) o de "molestia” (21). Según los ejemplos que construyeron para nosotros, este subtipo de actos expresivos parece impregnar la fuerza ilocutoria (eminentemente directiva) de los enunciados con vuestro. En estos ejemplos, los informantes recreaban la situación y formulaban los ejemplos más adecuados en cada caso (entre comillas):

(20) con un grupo de cinco y digamos que estoy apurada: "por favor ¿podrían facilitarme vuestros pasaportes?” (informante de origen rural en el Cuzco; encargada de una agencia de viajes / DGM2019)

(21) a. Una vez lo puedes limpiar tú; Ahora sí, la segunda: “¡ustedes tienen que limpiar vuestros zapatos!” (guía turístico, 30 años, Ollantaytambo, Cuzco / DGM2019)

b. ya molesto [...] “¡voy a responder vuestras preguntas!”, para que no me siga molestando (guía turístico, 30 años, Ollantaytambo, Cuzco / DGM2019)

En suma, el uso de vuestro está favorecido por diversos factores pragmáticos (tipo de acto de habla, ausencia de marca performativa explícita) y, con más claridad, los semánticos (significado específico, grupal, donde los miembros del grupo se relacionan a menudo, primero, individualmente con respecto al evento de la predicación y, segundo, en conjunto, por contraposición a la relación o actitud del emisor con respecto a tal evento). Los distintos factores se solapan o, más bien, contribuyen conjuntamente al uso de vuestro. Tomemos, por ejemplo, el caso de (7), donde un hablante nos preguntó ¿Ya se van a vuestros países?: a nivel semántico, hay referencia específica (el hablante nos está viendo en el momento de 
la interacción y, dado que ya habíamos hablado con él por extenso con anterioridad, nos conoce y, seguramente, recuerda que "nuestros países" de origen son Suiza y Alemania); hay, por otra parte, un contraste a nivel semántico-informativo (nuestros países no son el suyo) y, antes, una relación semántica individual, distributiva, para con el evento predicado dentro del grupo (cada uno de nosotros se va a su país correspondiente); todo ello, además, en el marco de un acto de habla directivo. El hablante crea, con todo ello, una contraposición entre su rol de persona local, que permanece allí viendo ir y venir a gente como nosotros, y nuestro rol de turistas o visitantes ocasionales. En especial, la tensión entre la percepción del grupo como entidad cohesiva que se opone a las circunstancias sociales o a la cosmovisión del hablante (por tanto, a nivel discursivo) y, al mismo tiempo, en no pocos ejemplos, como entidad de individuos que realizan independientemente la acción predicada (existiendo, a nivel semántico, un paralelismo interno al grupo), merecerá análisis más detallado en el futuro.

\subsection{El valor socioindexical: la buena formación}

En los apartados anteriores hemos presentado el valor de vuestro en la interacción discursiva, para la delimitación de grupos y la construcción de identidades sociales. Cabe preguntarse entonces en qué medida, en vista de lo expuesto arriba, aún tendría sentido relacionar los usos de vuestro con las categorías de análisis tradicional (de base psicosocial) en los estudios sobre tratamientos y, concretamente, en relación con la dicotomía entre formas $\mathrm{T}$ y formas $\mathrm{V}$, resultante de combinar los parámetros de poder y solidaridad, en la célebre tradición de Brown y Gilman (1960). Además, abordamos la cuestión del uso de vnestro desde un punto de vista estilístico: a este respecto, es necesario no caer en la confusión conceptual a la que a veces parece llevar la relativa ambigüedad del término "formalidad": unas veces utilizado desde la perspectiva, ya mencionada, de la Psicología Social, y equiparado entonces con la distancia o con el respeto para con el interlocutor y otras veces empleado desde la 
perspectiva de la Lingüística de Variedades - Varietätenlinguistiky entendido entonces como las circunstancias que desencadenan un registro o "estilo formal”. Dado que las diferentes dimensiones variacionales se vinculan entre sí en función de la relación "dialecto $\rightarrow$ nivel $\rightarrow$ estilo de lengua” (Coseriu 1982: 19-24) ${ }^{8}$, observaremos el condicionamiento social (diastrático) de las diferencias de estilo (diafásicas). Finalmente, a partir de la percepción del uso de vuestro como parte de un "nivel” específico dentro de la sociedad, atenderemos a su valor socioindexical, que nos parece un aspecto clave para comprender la preferencia de su uso (frente al más neutral, socioindexicalmente no marcado, su).

Son muchos los informantes que perciben el uso de vuestro como una marca de formalidad o de respeto, percepciones que nos llevarían a incluirlo en el ámbito de una forma V. Esta opinión es frecuente sobre todo en los hablantes de la ciudad: "con amigos no, solo con gente que no conozco [...] como que muy formal”, "como que suena más formal decir vuestra que su paciencia" "el vuestro es más de respeto", "considero esta palabra como una palabra de respeto", etc. A su vez, los informantes citadinos que consideraron vuestro como algo más propio del ámbito rural explicaban su uso como "un poquito limitando", esto es, marcando la distancia con los oyentes, ya que consideraban a los habitantes del medio rural como "más reservados". Sin embargo, la valoración real de los propios hablantes del medio rural no incluye siempre el carácter de formalidad, pudiendo, incluso, invertirse esta consideración, como en la opinión, ya comentada, de dos informantes femeninas de Ollantaytambo que explicaban el uso de vuestro "cuando hay más confianza”, es decir, como algo más próximo a una forma T.

En realidad, esta ambivalencia del valor psicosocial de vuestro manifestaría solo una aparente contradicción; de hecho, los estudios sobre tratamientos ya han enfrentado con anterioridad este tipo de

8 En su formulación más básica, puede atenderse al funcionamiento de la Varietätenkette en el modelo, no menos de célebre, de Koch y Oesterreicher (2011: 16-17), en el que no entraremos aquí. 
problemas. Repasando: por un lado, es obvio que el uso de vuestro es característico de muchos discursos en los que, efectivamente, va ligado al respeto; por otro, también se registra ampliamente en el hogar familiar, especialmente - hasta donde hemos podido documentar - en órdenes y reproches de padres a hijos (ejemplos (3)-(5)). Seguramente, a los colegas conocedores de la bibliografía sobre tratamientos esta situación les sonará familiar, relativamente próxima a la del uso de usted, que, en algunas áreas del dominio hispanófono, puede ser tanto forma de respeto como de intimidad o cariño -incluyendo en este último ámbito, por ejemplo, el enojo para con los seres queridos, como en los reproches de padres a hijos-, sin que llegue a ser la forma escogida para otros tipos de relación de confianza (es decir, no se trata del "ustedeo", frecuente en otras partes de América, que conlleva el desplazamiento efectivo de la forma originalmente $\mathrm{T}$ por la forma originalmente $\mathrm{V}$, tal como encontramos en la diacronía del inglés - con la sobregeneralización de you - o en portugués de Brasil — con la de você-). En la parte final de un trabajo sobre los pronombres de tratamiento singulares y sus "valores expresivos" en Argentina, Perú y Puerto Rico, se concluye:

El caso de fluctuación más común es el que se da en las relaciones completamente solidarias donde prevalece el tuteo; se dan casos en que, por disensiones serias, puede producirse un distanciamiento pasajero y momentáneo. En estas circunstancias la persona que posee mayor autoridad, haciendo prevalecer la jerarquía sobre el afecto, suele usar transitoriamente el usted (Solé 1970: 189).

En estos casos, en vez de una dicotomía usted $(\mathrm{V})$ - tú vos (T), se hablaría de una relación usted - tú vos - usted (v. también Hummel 2010 para el caso chileno y Uber 2011 para una fundamentación teórica de este doble uso de usted). De manera análoga, cabría pensar aquí, para la 2P.PL (aun solo a través de las formas posesivas), en una relación igualmente triádica del tipo vuestro - su - vuestro. 
Sin embargo, necesitaríamos más datos para fundamentar (o refutar definitivamente) la anterior hipótesis, que, en todo caso, se plantea solo con respecto a algunos hablantes: tal vez más a menudo en aquellos pertenecientes al ámbito rural o ligados aún a este, aunque puedan haber migrado a la ciudad. Por ahora, no pensamos que el factor decisivo para entender la selección de vuestro o de $s u$ tenga que ver con la mayor confianza o respeto asociada con una u otra forma. Sí creemos, en cambio, que puede haber un condicionamiento estilístico o, mejor dicho, un condicionamiento sociológico que determina la preocupación y percepción del buen estilo como símbolo de buena formación.

Un informante definió el vuestro como "más presentable" y "más elegante". Otra informante explicaba el uso habitual de vuestro por parte de políticos porque "cuanto más floro, más te van a entender”. Este tipo de marcas ('elegante', 'florido', etc.) son típicamente estilísticas. No obstante, la mayoría de entrevistados llegaban finalmente a la conclusión, formulada de un modo u otro, de que la preferencia por vuestro "viene de la formación”. Un informante boliviano (paceño) asentado en el Cuzco, que ha tenido que acostumbrarse y aprender a usar el vuestro cuzqueño, lo relaciona con la "calidad": gracias a su uso "eres más grande" (se observa así la diferencia entre este uso ligado a la grandeza del hablante y el recurso de cortesía positiva, habitual en la conformación de muchas formas de tratamiento, de ensalzar la grandeza del oyente). En una línea semejante, incluso la hablante que más recelos mostraba en relación con el propio uso de vuestro (cuzqueña citadina, 32 años), admitía que era posible "si [el hablante] es alguien súper súper importante”. Otra informante, de edad avanzada, actualmente librera, pero con experiencia laboral como maestra de escuela, relacionaba las variantes con vuestro con la educación ${ }^{9}$ y no faltaban quienes consideraban vuestro como la variante "culta”. En definitiva, su uso está vinculado con la formación. Dado que esta

9 Concretamente, en el momento de manifestar esta opinión, la informante se estaba refiriendo a las diferencias entre las variantes Abróchense vuestros/sus/los zapatos. 
constituye un valor social ponderado que, de manera estratégica o no es puesto en alza, la utilización de vuestro queda también atada a la calidad personal. Lo interesante es que la gran mayoría de los hablantes tienen claro que la formación no es solo cosa de la escuela, sino que "más que todo viene del hogar la formación”, en virtud de lo cual entendemos mejor que vuestro tenga cabida tanto en el ámbito público como en el privado o familiar.

\section{Desafíos sociohistóricos para la investigación futura}

5.1. La diatopía del paradigma-u/v: campo y ciudad, región andina surperuana y otras áreas

El paradigma-u/v se encuentra tanto en la ciudad del Cuzco como en otras localidades más pequeñas del departamento (v. ejemplos (1), (4) y (5)), aunque cabe la posibilidad de que las dinámicas sociolingüísticas sean parcialmente distintas en el ámbito urbano y en el rural. Sobre todo, los hablantes jóvenes (por debajo de 30 años) de la ciudad parecen usarlo menos y, en algunos casos, haber desarrollado una conciencia negativa con respecto a este fenómeno. Hay que tener en cuenta, no obstante, que algunos de estos jóvenes tampoco tienen una valoración necesariamente positiva de su ciudad, a la que consideran provinciana y carente de grandes oportunidades laborales aparte del turismo, por oposición a Lima, a la que parecen identificar con la modernidad. Es decir, en este tipo de informantes sería esperable una mayor presión de la "norma limeña” (aunque nadie sepa en qué consiste esta exactamente, sí está claro al menos que, con las reservas hechas en $\$ 3.2$., la capital peruana tiende a usar exclusivamente la forma su como posesivo de 2P.PL).

Una joven citadina de tercera generación (sus padres se habían criado también ya en la ciudad y eran solo los abuelos los que mantenían contacto estrecho con —o vivían en- el medio rural) nos decía que el vuestro plural era “quizá más rural”, aunque no descartamos que esta valoración se desprendiera del estereotipo - bastante extendido- de que la gente "en el campo son más amables". Sin 
embargo, también varios informantes citadinos consideraban que es un rasgo propio del habla adulta, siendo típico en gente de mediana edad y muy raro entre niños (aunque estos últimos puedan recibir de sus maestros el tratamiento de vuestro). Más concretamente, algunos jóvenes de la ciudad en edad laboral (vendedores, recepcionistas de hotel, etc.) nos informaron de que el uso activo de este tratamiento se desarrollaba al entrar en el mercado laboral, por lo que lo asociaban con la praxis cotidiana del proceso de profesionalización; de hecho, su uso se percibe también como muy frecuente en el contexto de reuniones de empresa.

Si bien es cierto que el juicio repetido más a menudo cuando se les preguntaba a los informantes por las diferencias entre vuestro y $s u$, era considerar el primero de ellos "más formal” (excluyendo los casos en los que el segundo se rechazaba de plano por "ambiguo" o por su primera asociación con un significado singular: v. \$3.1), es necesario destacar que dos informantes de Ollantaytambo, oriundas de la localidad y responsables de un restaurante aseguraban que nunca tratarían de vuestro a los clientes, ya que esta forma va acompañada de "más confianza" y de un cierto conocimiento de los oyentes. No sabemos si este juicio apunta a un uso parcialmente diferente de vuestro en el campo y la ciudad. Por una parte, hay que advertir que este juicio tuvo lugar después de que ambas produjeran (y posteriormente, comentaran por extenso) variantes como las de los ejemplos (3) y (4), que consisten en órdenes, por lo que es probable que al hacer su valoración del fenómeno aún tuvieran en mente este tipo de contextos (evidentemente, inadecuados para clientes). Por otra parte, no pasa desapercibido el que la mayoría de ejemplos de vuestro en el ámbito familiar ((3), (4) y (5)) fueron producidos por los informantes de localidades más pequeñas como Ollantaytambo o por los oriundos del ámbito rural (aunque pudieran haber migrado a la ciudad), mientras que los informantes citadinos asociaran el uso de vuestro, antes que nada, con la vida profesional, con la radio, los discursos políticos y otros contextos oficiales.

Para comprender mejor esta aparente diferencia entre la ciudad y la provincia, podemos aferrarnos al testimonio de otro informante 
de Ollantaytambo acerca del uso de vuestro entre amigos o en el ámbito familiar: para él, en estos casos, "eso viene de la casa [...] de la formación de cada persona", siendo difícil imaginar el uso de vuestro (y de otras expresiones "elegantes") en el seno de "familias disfuncionales". En realidad, a tenor de este tipo de juicios, es claro que el uso de vuestro parece tener más que ver con la "formación" que con la "formalidad", esto es, más con la formación del hablante $\mathrm{y}$ con sus intenciones comunicativas que con formalidad del trato al oyente en una situación dada (v. \$4.3). Y, en este aspecto, así como en lo que concierne al valor discursivo de contraste, el uso en el campo y en la ciudad van de la mano.

Como adelantábamos en $\$ 2$, seguramente lo más específico del uso de vuestro plural en español cuzqueño es su "normalización" - concepto que entendemos aquí tanto de manera precientífica, en línea con el juicio de la informante de $\$ 3.2$. , que consideraba "muy normal" este uso, como de manera lingüística, ya que, si entra regularmente en el habla de los cuzqueños educados, en la lengua de los medios de comunicación (ejemplos (11) y (12)) y en los discursos del gobierno regional (ejemplo (2)) o de las máximas autoridades eclesiásticas (ejemplo (9)), no cabe sino considerarlo parte de la norma cuzqueña. Esta normalización del fenómeno en español cuzqueño no implica, sin embargo, que no pueda registrarse en otras partes.

La falta de descripciones concretas en relación al fenómeno estudiado fuera del Perú, nos llevaría, en principio, a deducir que es poco frecuente. Sin embargo, somos conscientes de que el estudio de la 2P.PL ha estado mucho más desatendido que el de la 2P.SG (cuando no completamente abandonado) y de que, en general, la falta de estudios precedentes no implica nada con respecto a la existencia o no de un fenómeno dado (de hecho, el que estemos estudiando el vuestro cuzqueño se debe, en última instancia, a casualidad ${ }^{10}$ ). El resto de este apartado se dedica a presentar algunos

10 Si los dos autores de este trabajo, uno con experiencia en el estudio de las lenguas y culturas andinas y el otro con experiencia en el estudio de los tratamientos en la historia del español de América, no se hubieran conocido en la región en 2016 (en el marco de un 
datos y algunas primeras intuiciones sobre el uso del paradigma-u/v fuera del Cuzco.

El testimonio de Hildebrandt visto en $\$ 3.2$ parece hablar a favor de una cierta presencia de uso del paradigma-u/v en otras partes del Perú, incluyendo Lima, "hasta en textos [...] del más alto nivel" (¿o quizá solo en ellos?). Por distintas informaciones que colegas y amigos peruanos nos han hecho llegar, el fenómeno aparece - $-\mathrm{y}$ quizá no solo marginalmente- en otras regiones del Sur de Perú, especialmente en Arequipa. Además, el paradigma-u/v parece accesible a algunos hablantes de Argentina, Bolivia, Chile y Ecuador, y seguramente de otras partes. Algunos ejemplos son los siguientes:

(22) ¡Cuiden vuestras espaldas! (instructora de yoga de origen arequipeño en una clase dada en Lima. 21.1.202011)

(23) Me interesaría conocerlos y realizar una sesión de trabajo con ustedes [...]. Me gustaría recibir vuestro apoyo en el tratamiento de la información de campo (colega ecuatoriana preguntando por email a varios lingüistas acerca de posibilidades de colaboración. 26.1.2020)

(24) Lo mejor que pueden hacer es ustedes crear vuestras propias estructuras (fundador chileno de una cooperativa agrícola en Alemania en una entrevista de una emisión radial alemán-chilena. 16.7.2020) ${ }^{12}$

(25) Bueno, es eh... mira, mamacita, eso es recíproco. Porque cuando yo, nosotros escuchamos la música vuestra también. De verdad ¿no? (músico folclórico boliviano, de Oruro, reaccionando al cumplimento de la conductora del programa televisivo en que es entrevistado, que también hace música profesional. 28.6.2017). ${ }^{13}$

(26) He bajado para dar la cara y hablar con ustedes como corresponde. Quiero manifestarles mi absoluta solidaridad con vuestra situación (reproducción de las palabras del gobernador de Tucumán,

congreso organizado en Pisac por los colegas de la PUCP) y no hubieran advertido in situ el frecuente uso del paradigma-u/v, no se habrían decidido a estudiarlo.

11 Agradecemos, de nuevo, a Luis Andrade su generosidad en compartir con nosotros este ejemplo.

12 Agradecemos a Adriana Orjuela su generosidad en compartir con nosotros este ejemplo.

13 Agradecemos a Mario Soto Rodríguez su generosidad en compartir con nosotros este ejemplo. 
Argentina, según se recogieron en un periódico de Bahía Blanca, de donde, a su vez, Fontanella de Weinberg 1999: 1404 tomó el ejemplo. 16.2.1995)

Además, son interesantes algunos datos del reciente trabajo de Morgan y Schwenter (en prensa), en el que, además de presentar algunos ejemplos más de vuestro en Argentina y Ecuador, estudian los usos residuales de las formas de vosotros en el español americano actual a partir de una encuesta online que respondieron 217 participantes de toda Hispanoamérica. Aunque el 78\% de los encuestados respondieron que nunca usarían vuestro (porcentaje de rechazo muy próximo, por cierto, al obtenido para las formas vosotros y os), llama la atención que "some respondents asserted that vuestro [...] was actually a member of the ustedes paradigm, as a formal (and presumably disambiguating) form for possessive $s u$ ". Suponemos que las personas que describieron la existencia del paradigma-u/v pertenecían al 1,4\% (3 encuestados) que dicen utilizar vuestro "muy a menudo", al 4,7\% (10 encuestados) que lo hacen "alguna vez" o, cuando menos, al 15,9\% (34 encuestados) que lo hacen "rara vez". Aunque no se indica la región o país de origen de los informantes que, en mayor o menor grado, aceptan vuestro, estos datos apoyan nuestra propuesta principal aquí: que el paradigma-u/v está de alguna manera accesible a hablantes de algunas otras regiones de América.

Sin embargo, no sabemos si en estas otras regiones vuestro aparece con una frecuencia semejante a la que presenta en el Cuzco o si lo hace solo en ejemplos relativamente aislados (en cuyo caso tendría un peso pragmático mayor, esto es, un valor de estrategia retórica más marcada que en el Cuzco). No hemos podido averiguar aún, por ejemplo, si en el Tucumán (ej. 26) el paradigma-u/v es forma de uso general para el tratamiento de un gobernador a una multitud, ni tampoco en qué otros contextos resultaría válido tal paradigma. Dado que - en homenaje a aquel trabajo clásico (y póstumo) de Fontanella de Weinberg (1999)— decidimos incluir esta misma frase (ej. 26) en el cuestionario final de nuestras entrevistas (sin advertir que había sido pronunciada por el gobernador tucumano y no por el cuzqueño), pudimos observar que para todos 
nuestros informantes cuzqueños el ejemplo sonaba perfectamente posible (incluso aquellos que decían no usar ellos mismos el paradigma-u/v, consideraban que este ejemplo sería típico en boca del gobernador regional).

El ejemplo (22), de Arequipa, y otros que nos han hecho llegar de esta ciudad, nos hacen pensar que el uso arequipeño se aproxima mucho al cuzqueño, siendo posible, tal vez, hablar de un uso general de vuestro plural en el español surandino peruano. Quizá, yendo un paso más allá, el rasgo podría redefinirse como "surandino" en general: de este modo, podrían tener cabida en grandes áreas del español chileno (ej. 24) y del boliviano. De hecho, el ejemplo (25) confirma que el fenómeno, aunque los paceños entrevistados tiendan a rechazarlo, puede registrarse al menos en provincias y áreas rurales de Bolivia. Además, en la medida en que, en perspectiva histórica, es asumible que algunas soluciones surandinas se extendieran siguiendo la ruta de la plata, no descartamos que el fenómeno exista o haya existido en el área rioplatense; esta ruta incluiría, como transición del mundo andino al no andino dentro del noroeste argentino, la región del Tucumán (ej. 26). Por último, dando cabida al ejemplo ecuatoriano de (23), no descartamos que pueda tratarse de un rasgo "andino" en general. En realidad, ni siquiera descartamos el que pueda documentarse ocasionalmente en algunas otras partes de América. Sea como fuere, los datos de fuera de la región cuzqueña son, a día de hoy, tan escasos que no podemos extraer conclusiones de ningún tipo, aunque no por ello pase desapercibida la relativa contigüidad de las áreas geográficas mencionadas dentro de Sudamérica, sobre todo, si pensáramos que el uso ocasional del fenómeno en el área rioplatense llegó allí desde la región surandina, una hipótesis que futuras investigaciones diacrónicas se encargarán de confirmar o refutar. En el apartado siguiente $(\$ 5$.2.) presentaremos un recorrido general por la historia de vuestro plural en el español cuzqueño y surandino, pero somos conscientes de la necesidad de estudiar históricamente la competencia, a menudo difícil de aprehender, entre el paradigma-u/v y los otros dos paradigmas en las otras regiones donde hoy se documenta 
vuestro plural (pensamos, por ejemplo, en los datos de Zamora Salamanca 2006: 606-607 sobre traducciones argentinas de novelistas anglófonos - Dos Passos, Faulkner, etc.- en la primera mitad del s. XX, donde predomina el paradigma-u y, secundariamente, el paradigma-v, pero donde también llega a aparecer ocasionalmente el paradigma-u/v).

Futuras investigaciones de campo habrán de resolver el problema de la distribución areal del fenómeno o, en realidad, del conjunto de fenómenos, ya que es probable que, en todo caso, las frecuencias varíen de unas zonas a otras en función de los tipos de contexto y de uso (formulaico vs. estratégico, pudiendo las estrategias comunicativas ser también parcialmente distintas en cada zona). A su vez, teniendo en cuenta lo expuesto en \$3.1., será necesario determinar en cuáles de estas zonas vuestro es, como en el Cuzco, exclusivamente plural.

A pesar de todo lo dicho, es evidente la relativa especificidad del uso cuzqueño (o, quizá, surandino peruano) con respecto a dos grandes centros normativos relativamente próximos: los correspondientes a las capitales Lima y La Paz. Las descripciones lingüísticas de las variedades que circulan en ambas ciudades han movido mucha bibliografía, en la que no hay referencias a ningún vuestro plural. Además, las percepciones de los hablantes nos sirven de ayuda. Los hablantes oriundos de estas dos capitales que entran en contacto con cuzqueños (por ejemplo, turistas limeños o trabajadores bolivianos emigrados) perciben rápidamente el uso cuzqueño de vnestro plural, que consideran ajeno a sus variedades capitalinas. Así, como ya anticipamos, un informante boliviano (originario de La Paz), residente desde hace cinco años en Cuzco, donde ejerce su profesión de vendedor de seguros para una importante compañía internacional y donde se casó además con una cuzqueña, nos contaba cómo tuvo que acostumbrarse a oír, interpretar e incluso utilizar el vuestro plural, el cual, en el ámbito familiar, es especialmente habitual en boca de su suegro y, en el ámbito profesional, es general en las reuniones de empresa. En su percepción, repetimos, con vuestro “muestras calidad... eres más grande”. Por su parte, en (27), 
recuperamos el testimonio metalingüístico que escribe un limeño en un foro de internet sobre el uso cuzqueño, que percibe como una diferencia lingüística con respecto a Lima y que, por cierto, parece valorar positivamente. Por último, en (28) completamos esta percepción foránea con la propia de un hablante de Ollantaytambo (acostumbrado a tratar con turistas hispanoamericanos y españoles y, por ello, con experiencia en otras variedades de español) cuando le preguntábamos por la extensión del uso de vuestro:

(27) La gente de Cuzco usa el segundo pronombre plural: VUESTRO (A) (S) mientras que la gente de Lima usamos USTEDES. Me agrada la forma cuzquena. (sciffo, 27-ene-2008, 17:23, Lima; forosperu.net, thread: "Diferencias entre Lima y las provincias" / Dankel y Gutiérrez Maté 2020: 353-354)

(28) Es que es el tema... llamémosle el tema del dialecto, o del dejo. Porque el chileno tiene otra forma de hablar, los limeños tienen otra forma de hablar, los que viven en la Amazonía... Aquí ha sido la mezcla. Nosotros tenemos el mestizaje. Aquí hay muchas palabras que de repente nosotros usamos de manera muy parecida al español. "Vuestras preguntas", "Voy a responder con vuestro permiso"... En Lima ya viene algo posterior. Aquí es por el tema del mesticismo[sic]... ¡mezcla! entre españoles e incas (Ollantaytambo, guía turístico, 30 años / DGM2019)

Retomaremos en $\$ 5.3$ algunas implicaciones de este testimonio (en relación con el "mestizaje"), el cual nos vale, por ahora, para apreciar la autopercepción del vuestro cuzqueño como algo propio de su dialecto: al menos, según esta persona ${ }^{14}$, ya que, en realidad, la

14 Reconocemos que podría haber cierta predisposición a indicar una marca dialectal cuzqueña en el uso de vuestro plural: en la primera parte de la entrevista nos presentamos como investigadores interesados por la identidad y especificidades culturales del Cuzco, por lo que no sorprendería que en la parte final, después de haber intentado elicitar ejemplos, cuando preguntábamos abiertamente por la extensión y significado de vuestro, quisieran presentarlo como algo también específico (y, por tanto, marcado diatópicamente) del Cuzco, para complacer a los entrevistadores. Sin embargo, la complicidad que se desarrolló con este informante (sobre todo después de tomar una bebida juntos, conocer a su esposa e incluso intercambiar pequeños regalos) creó una atmosfera comunicativa que hace muy difícil pensar que haya manipulado sus juicios lingüísticos conscientemente. 
mayoría no entraron en valoraciones dialectales y ni siquiera eran conscientes de que en Lima se hablara sin vuestro.

\subsection{La diacronía del paradigma u-v}

Uno de los aspectos de estudio que habrán de requerir mayor atención en el futuro es el de la historia de las formas de 2P.PL en español de Cuzco, paso necesario para la comparación con la historia de esta persona gramatical en otras zonas de Hispanoamérica. Concretamente, se habrán de identificar los usos y valores de vuestro, así como dar cuenta de la constitución misma del paradigma-u/v como el único resultado de la combinación del paradigma-v y del paradigma-u.

En principio, parece lógico pensar que el paradigma-u/v resultara de la fusión de paradigmas de vosotros y ustedes, como consecuencia del proceso (incompleto) de desplazamiento de vosotros por ustedes en la historia del español de América. Tal hipótesis encontraría fácilmente apoyo, además, en la bibliografía existente para otras áreas iberorrománicas como el suroeste de la Península Ibérica (Lara Bermejo 2015, 2020): en este caso, la sustitución del paradigma de 2P.PL por parte del pronombre de 3P.PL (ustedes/ vocês) se ha presentado como un proceso que consta de varias etapas, siendo la penúltima de ellas (antes de la sustitución completa de un paradigma por otro) aquella en la que el posesivo de 2P.PL combina con las formas tónicas, clíticas y desinenciales de 3P.PL (Lara Bermejo 2020: 83, 99), esto es, precisamente la correspondiente a nuestro paradigma-u/v (la analogía con el caso andaluz occidental — quepa aclarar- se destaca aquí solo en cuanto al paralelismo estructural, es decir, no se sugiere necesariamente una relación genética entre los usos a uno y otro lado del Atlántico, ni mucho menos coincidencias entre los valores discursivos y socioindexicales del fenómeno aquí descrito ${ }^{15}$ ). De hecho, conocemos

15 En primer lugar, aunque el desarrollo de este paradigma estructural coincida con uno de los que presenta el andaluz occidental, esto no constituye indicio de una relación genética entre ambos, de modo que el uno no tiene por qué provenir del otro: no 
otros casos en los que el posesivo resiste durante más tiempo la invasión de las formas pronominales de su paradigma: se registra, por ejemplo, como paso intermedio del proceso de sustitución del nos mayestático por el yo singular en cédulas reales de la Temprana Edad Moderna (Gutiérrez Maté 2013: 189-192) y lo hemos observado en la 2P.SG, en el proceso histórico de sustitución de vos por tú en las zonas hoy día tuteantes, como, precisamente, el Cuzco (Dankel y Gutiérrez Maté 2020: 331-334). Por su parte, el hecho de que la sustitución paradigmática no se completara en el Cuzco encuentra paralelismo en algunas variedades del portugués donde el pronombre vocês ha desplazado casi completamente a vós, salvo por el posesivo vosso; este paradigma se da en algunas áreas de Portugal (v. mapa en Lara Bermejo 2020: 88, “stage 3") y uno de los autores de este trabajo lo encuentra a veces en su corpus de entrevistas en Angola ${ }^{16}$ (por lo que respecta a Brasil, el posesivo suele ser el de 3P.PL o, más comúnmente, la forma analítica de vocês).

está clara la antigüedad del paradigma-u/v ni de los distintos paradigmas "híbridos" hallados en andaluz occidental, $\mathrm{y}$, en el caso improbable de que estos hubieran estado en español clásico y podido participar de manera decisiva en la constitución histórica del español cuzqueño durante la etapa colonial, no habría motivo para pensar que este origen andaluz determinara de alguna manera el uso que los cuzqueños hacen hoy de vuestro. En segundo lugar, el paradigma-u/v coexiste con otros dos paradigmas (el de ustedes y el de vosotros, cuyo uso no hemos podido documentar directamente pero damos por hecho, en la medida en que puede tener cierta existencia marginal en todo el Perú), resultando un tipo de variación que, a buen seguro, se concreta variacionalmente de manera distinta a como lo hace en Andalucía (donde, en términos generales, los paradigmas mixtos quedan en la oralidad, sin que alcancen nunca la distancia comunicativa: Narbona y otros 2011: 263-265).

16 El estudio del fenómeno en Angola sería de especial interés para su comparación posterior con el Cuzco: los hablantes que utilizan vosso inserto en el paradigma de vocês, en un caso, y los que utilizan vuestro inserto en el paradigma de ustedes, en el otro, son bilingües. Como en otros aspectos del portugués en este país (hablado por la mayoría como algún tipo de L2 “fosilizado"), la variación es grande en todos las dimensiones del diasistema y, antes, a nivel idiolectal. Además, los distintos esquemas que se presentan en el Suroeste de la Península Ibérica son a menudo difíciles de distinguir en el portugués angoleño por la aparición frecuente de otros fenómenos gramaticales (sobregeneralización del reflexivo se a todas las personas gramaticales, posible elisión o sustitución del dativo lhes por (pra) vocês, etc.). Sin embargo, algunos informantes parecían hacer un uso regular de vocês y todas las formas de su paradigma, salvo en ciertos contextos: entre ellos, de manera nada casual, se encuentra vosso en casos donde existe un contraste entre 
El desplazamiento de un paradigma por otro se entendería mejor, a su vez, si transcurriera paralelo a un desplazamiento funcional, ligado a una sustitución o neutralización semántica: por ejemplo, si ustedes y su paradigma-u hubieran sido anteriormente las formas de respeto (formas V) y vosotros y su paradigma-v las de confianza (formas T). De hecho, dado que en términos universales (tanto en la diacronía de muchas lenguas como en el nacimiento de "lenguas nuevas": v. Gutiérrez Maté 2019: 181-183) es mucho más común que la forma de tratamiento que salga triunfante de la neutralización de V-T sea la forma originalmente $\mathrm{V}$-que pasa entonces a significar V\&T-, el desplazamiento de vosotros por ustedes sería el cambio lingüístico predecible, lo que ofrecería una explicación natural para dar cuenta de la realidad actual del español americano, donde ustedes es la forma generalizada para todas las situaciones. Sin embargo, investigaciones recientes apuntan a que la especialización semántica de los dos pronombres (y sus respectivos paradigmas) nunca tuvo lugar en la etapa colonial y, por tanto, no pudo haber "neutralización" posterior alguna (Bertolotti 2020; García Godoy 2012: 130-131, 140); además, si la historia hubiera sido así, esperaríamos que el paradigma-u/v, en tanto que incluye un resto del paradigma-v, estuviera más próximo al valor de T que el paradigma-u, lo que no es necesariamente cierto. En realidad, es justo decir que aún no entendemos con claridad cómo funcionaba la convivencia entre las formas de 2P.PL ustedes (/vuestras mercedes) y vos(otros) durante el período colonial (produciendo alternancias de distinto tipo, quizá no tan distintas de las observadas en el español peninsular de la época: Calderón Campos 2019: 147-150). Sabemos que el sistema de tratamientos de plural (al igual que sucedió con

el emisor plural y los destinatarios (ele tá perguntar [...] o nosso tempo e o vosso tempo é diferente, não é?) y en ciertas fórmulas rutinizadas (a vossa vontade, a vossa vantagem —en el sentido de 'mejor para ustedes'-, etc.). Si bien este fenómeno concreto no se ha estudiado antes, la descripción de una parte del corpus y de algunos problemas del estudio del portugués de Angola puede verse en Gutiérrez Maté (2020). 
los tratamientos singulares ${ }^{17}$ ) finalmente vio reducido su inventario de formas activas, lo que se concretó en la generalización de ustedes para todas las situaciones, pero no está claro por qué tuvo lugar tal simplificación ni por qué ustedes fue la forma escogida, a diferencia de España, donde hubo un mantenimiento de ambas formas, con la especialización de vosotros para $\mathrm{T}$ y de ustedes para $\mathrm{V}^{18}$ (siendo incluso la primera forma la que parece predominar sobre la segunda, si aceptamos la propuesta de Morgan y Schwenter 2016).

Frente a las incertidumbres que aún hoy genera el estudio de la 2P.PL en el período colonial, el siglo XIX americano está mejor descrito: se asume, así, que vosotros (y el paradigma-v) experimenta una revitalización y especialización como marca de formalidad, por ejemplo, para discursos políticos (Caravedo 2019; Frago Gracia 2011: 57; Bertolotti 2007: 24-27); de hecho, los usos residuales del paradigma-v en el español peruano actual (v. \$3.2) parecen ser restos de esta situación del siglo XIX. Por nuestra parte, no estamos convencidos de que hubiera una auténtica revitalización del paradigma-v, como veremos, pero su especialización nos parece clara (y esperable, dadas las transformaciones sociales de esta centuria). Desconocemos, sin embargo, si los cambios más importantes con respecto a la generalización de ustedes en español americano general y a la formación del paradigma-u/v en el Cuzco y algunas otras regiones ya habían tenido lugar en la época, aunque no se mani-

17 De las cuatro formas de 2P.SG (tú,vos, vuestra merced/usted y él/ella), las cuales, a pesar de algunos solapamientos inevitables ya en la época (Anipa 2001: 207), presentaban dominios funcionales parcialmente diferenciados, quedaron generalmente dos, a veces tres (sistema III de Fontanella 1999, con tú, vos y usted), y a veces solo uno (en las zonas de ustedeo). Hummel (2020) plantea que una parte de la evaluación diacrónica de los tratamientos en español y portugués responde a la necesidad de resolver las "crisis" que generan la convivencia de varias formas de tratamiento; la neutralización de las diferencias semánticas de unos tratamientos y otros es una posible salida de la crisis.

18 En el siglo XIX tuvo lugar, definitivamente, la especialización de vosotros como forma T en España (Fernández Martín 2012). Con anterioridad a esa época, también para el caso del español peninsular, faltan certezas sobre el valor de las distintas formas de 2P.PL, a pesar de algunas diferencias pragmáticas de interés observadas por Calderón Campos (2015: 73-75) ya en documentos malagueños de la primera mitad del siglo XVII (v. también Calderón Campos 2019). 
fiesten apenas en textos, siendo entonces ajenos a los desarrollos de vosotros en ciertas tradiciones discursivas de la distancia comunicativa, o si, por el contrario, aún debieron esperar hasta bien pasado el período de Independencias para cumplirse, de modo que, al incorporarse vuestro al paradigma-u/v, pudo traer consigo algo del nuevo uso decimonónico del paradigma-v.

Presentaremos, más adelante, testimonios históricos de Cuzco y el área surandina, pero, en todo caso, sea cual sea la cronología de los cambios (en la época (tardo)colonial o bien avanzado el siglo XIX), los procesos serían esencialmente los mismos. En nuestra opinión, además de la sustitución/neutralización de paradigmas (solución general en América) y del mantenimiento/especialización (general en España), pudo haber una tercera vía, la de la hibridación (en el Cuzco y las regiones que presentan el paradigma-u/v). Además, este paradigma no representaría simplemente un paso intermedio del proceso expansivo de ustedes, sino que resultaría de la combinación de formas de uno y otro paradigma en función de las estrategias comunicativas y de las necesidades discursivas de los hablantes. Estos, como es evidente, no se preocupan en mantener los paradigmas etimológicos de cada persona gramatical, sino que escogen del inventario de formas que ofrece la lengua aquellas que mejor se adaptan a sus intereses. Una posible explicación de por qué, entonces, los hablantes cuzqueños sintieron la necesidad de quedarse con dos formas del posesivo y dotar a una de ellas (vuestro) del significado — social y discursivo- que hemos expuesto en $\$ 4$ tiene que ver con el contacto cultural y lingüístico (v. \$5.3).

De lo expuesto con anterioridad se deduce la necesidad de rastrear la formación del paradigma-u/v en textos. A este respecto, cabe admitir que aún no hemos emprendido este trabajo de manera exhaustiva, lo que exigiría primero la constitución de un corpus extenso con distintas fuentes documentales, literarias, periodísticas, etc., correspondientes a los cinco siglos de historia lingüística cuzqueña. Un corpus de estas características contribuiría a seleccionar una o varias de las hipótesis diacrónicas planteadas en Dankel y 
Gutiérrez Maté (2020: 328-352) ${ }^{19}$. La tarea se presenta ciertamente difícil: por una parte, los textos con destinatario plural son relativamente escasos - en comparación con aquellos con destinatario singular-, sobre todo en el ámbito de la inmediatez comunicativa (cartas privadas, fragmentos en estilo directo en autos judiciales, etc.); por otra, la naturaleza híbrida del paradigma-u/v hace su documentación difícil de distinguir de la alternancia de tratamientos: en otras palabras, para estar seguros de que no estamos simplemente ante casos de address switching (v. Anipa 2001, Gutiérrez Maté 2019), habría que encontrar tanto vuestro como alguna/s de las formas de ustedes dentro de una misma oración. En lo que resta de apartado recopilamos las informaciones dispersas en la bibliografía precedente y la combinamos con algunos ejemplos obtenidos durante nuestro primer rastreo en textos históricos de la región cuzqueña.

En teoría, al menos, los resultados de combinar vosotros y ustedes en América pudieron ser varios al principio y convivir entre sí; seguramente, además, estos resultados dieron lugar a variación diatópica (y de otros tipos), pudiendo ser también la cronología de la formación de unos u otros paradigmas distinta en cada región. A principios del s. XIX contamos ya con no pocas manifestaciones de la mezcla de los dos paradigmas: así, por ejemplo, en la correspondencia de una familia porteña, analizada por Fontanella de Weinberg (1971), si bien el autor al que corresponde el ejemplo estaba asentado en Tucumán en el momento de escribir la carta (ej. 29); por su parte, el ejemplo de (30) está tomado del Diario de José Santos

19 En Dankel y Gutiérrez Maté (2020) formulamos tres hipótesis diacrónicas (en gran medida, complementarias) sobre el origen de vuestro centradas en posibles evoluciones del español: (1) la resistencia del vuestro (SG y PL) durante la sobregeneralización de otros paradigmas pronominales (los de tú y ustedes, respectivamente) o incluso su extensión de SG a PL; (2) su idiomatización a partir de documentos dispositivos coloniales (desde cédulas reales a bandos municipales) y (3) la revitalización del vuestro en el español americano del siglo XIX. Como estas hipótesis no daban cuenta del hecho de que el vuestro se limita al español de Cuzco, sugerimos que el contacto lingüístico (específicamente una transferencia nocional del quechua sureño al español) y la idiosincrasia de la sociedad cuzqueña en la conformación de su identidad específica proporciona la explicación complementaria que faltaba. 
Vargas (1814-1825), comandante boliviano natural de Oruro, que con frecuencia reproduce pasajes en estilo directo (ejemplos similares de la obra han sido recogidos por Frago Gracia 2011):

(29) vosotros discurren y disponen mui bien por que están en la tierra de la jarana (Tucumán, 1812, carta de Tomás de Anchorena a su hermano / Fontanella de Weinberg 1971: 512-513)

(30) ¿Por qué hablan vosotros contra la Patria? ¿No son vosotros como he dicho americanos y no que se meten a ser enemigos de ella? (Bolivia, 1819, un "indio cantor medio cholo", ebrio, gritando a un grupo de indígenas; Vargas [1819]1982: 289)

En ambos ejemplos el pronombre vosotros combina con formas verbales de 3P.PL, si bien en la época hay otros resultados posibles de la fusión de vosotros y ustedes, como en otro ejemplo andino, de 1799, tomado de una obra de teatro boliviana, al que se han referido ya varios autores (Frago Gracia 2010; García Godoy 2012; Dankel y Gutiérrez Maté 2020):

(31) Yo les mando a los dos que pronto hagáis amistades (Potosí, Bolivia, 1799 / Arellano y Eichmann 2005: 216)

Llama la atención que muchos de los primeros ejemplos con mezcla de paradigmas provengan del área andina o regiones vecinas. De hecho, los testimonios más antiguos que encuentra Frago Gracia (2010: 244-247) corresponden igualmente al área surandina y, concretamente, a la quechuahablante. El más antiguo (1754) está en la leyenda de una pintura cuzqueña; en este ejemplo, el sujeto vnesas mercedes combina con un verbo en 2P.PL y con el posesivo analítico de ustedes (ej. 32). El segundo de mayor antigüedad (1783), hallado en un documento de archivo, constituye, hasta donde nos consta, la primera documentación del paradigma-u/v y está puesta en boca de "indios" de Cochabamba (a modo de canto de sublevación) (ej. 33):

(32) Contemplad vuesas mercedes / a Satanás del Rivero / resibiendo mojicón fiero / para escarmiento de ustedes (Cuzco, 1754 / Frago Gracia 2010: 245) 
(33) Viva nuestro Rey Tupacmaru y muera Carlos III, los chapetones vístanse de acero para defender a vuestro Rey Carlos III (Cochabamba, 1783 / Frago Gracia 2010: 245, documento del AGI, Charcas 736)

A pesar de todo, los registros escritos de la hibridación de paradigmas son relativamente escasos, incluso en el área surandina. Lo que, generalmente, encontramos en los textos antiguos es o bien el paradigma-v o bien el paradigma-u. La variación entre estos y el paradigma-u/v se presenta como un aspecto clave para la investigación futura; concretamente, determinar las funciones del paradigma-v en el período tardocolonial y durante las primeras décadas de historia republicana parece un paso previo para entender las que adoptó el naciente paradigma-u/v. Observamos, por ejemplo, que el paradigma-v aparece en el ambiente sociopolítico previo a la independencia, en las últimas décadas del s. XVIII, en la literatura satírica peruana para dirigirse al conjunto de los ciudadanos. La parte final de uno de los pasquines comentados por Godenzzi (1995: 73) correspondiente a la ciudad de Arequipa dice así:

(34) Y así nobles ciudadanos / en vuestras manos está / el que gocéis sin pensión / todas vuestras posesiones / quitándoles la vida a estos / ruines infantes sayones (Arequipa, 1780)

Este uso perdura después de las Independencias. En Perú y otras partes de Hispanoamérica, el paradigma-v al completo es habitual en el siglo XIX en discursos políticos, arengas militares, himnos nacionales y, en general, en discursos, que, como (34), se dirigen a los “ciudadanos" (v. el texto de Artigas comentado por Bertolotti 2020: 301), un contexto en el que hoy sería frecuente el paradigma$\mathrm{u} / \mathrm{v}$. Las alocuciones a los ciudadanos o al pueblo en general se encontraban también como parte de "verdaderas composiciones de claro contenido político que procuraban tener forma artística con un ritmo populachero" (Glave 2004: 200) [el énfasis es nuestro] en carteles publicitarios de diverso tipo, incluyendo al final de los carteles de corridas de toros, como en el siguiente ejemplo, tomado del facsímil que presenta Glave (2004: 201): 
(35) Al par del contento y gozo / Con que el Cusco recibió / A su Protector, que vio / Aquel placer y alborozo; / Yanacocha presuroso / Viene, con vivo interes / Al que ha sido, será, y es / Su dicha, su bien, su vida / Y le obsequia esta corrida / Humildemente a sus pies. / Ejército Vencedor / Unido con tiernos lazos / Estrechemos nuestros brazos / Con el mas cordial amor / Yanacocha aquel Pabor / Testigo de vuestra gloria / Recordando la victoria / De Socaboya y otros puntos / Os saluda a todos juntos / Con la más grata memoria (Abacuay —a menos de $200 \mathrm{~km}$ al oeste del Cuzco-, $1839^{20}$ )

Los ejemplos (34) y (35), tomados en conjunto, hacen dudar, primero, de la supuesta "formalidad" del paradigma-v, ya que no solo aparecía en textos solemnes patrióticos (como aquellos que terminaron cristalizando en himnos nacionales) sino también en géneros literarios menores y "populacheros”, y, segundo, de la propia "revitalización” de vosotros en el s. XIX, ya que este parecía estar bastante vivo también a fines del XVIII. Lo que sí pudo haber es un reciclaje y potenciación de su uso al amparo de las nuevas tradiciones discursivas que nacen después de las Independencias.

También en los editoriales de periódicos del s. XIX es regular el paradigma-v, como en el siguiente fragmento, en el que el periódico cuzqueño El Duende responde a otra publicación anterior:

(36) Respetables habitantes del departamento. Aunque parezca abusar de la bondad con que habéis dispensado alguna estimación al Duende, séame permitido ocupar las páginas de este número en defensa del Jefe de los Duendes. El núm. 44 de la Minerva (del 3 de julio) motiva mi queja [...] (El Duende N8, Cuzco, 6 de julio de 1830, en Glave 2004: 121)

Es notable que (34)-(36) se dirigen a un público amplio, a un grupo cuya referencia, no obstante, es específica; a los miembros del grupo se les concede el atributo — con no pocas implicaciones en la época- de "ciudadanos" y, además, se conocen los intereses

\footnotetext{
20 El texto celebra las victorias de Santa Cruz en Yanacocha y Socabaya que habían dado lugar al nacimiento de la Confederación Perú-Boliviana. El cartel también presenta otro texto interesante (en el que se nota la rivalidad de esta provincia con el vecino Cuzco), con la peculiaridad de estar escrito en quechua (Glave 2004: 202).
} 
que llevan a estos a leer estos textos y su capacidad de actuación. La formalidad, e incluso cierta cortesía positiva ("nobles ciudadanos", “respetables habitantes”) están presentes, al igual que -lo que es más importante aún- el valor de alocución a un grupo, del cual se excluye el hablante primeramente, para pedir después su respaldo e intentar persuadirlos en algún sentido.

En el interior de los periódicos es frecuente la aparición de textos literarios, incluyendo muchos dialogados, en los que seguimos encontrando o bien el paradigma-u o bien el paradigmav. Podemos ejemplificar este último con un fragmento del mismo periódico de arriba, en el que un personaje ficticio, uno de los llamados "duendes", de aparición regular en los pasajes narrativos del periódico, es encargado de visitar monasterios (considerados "bisagras entre el mundo criollo nuevo y el viejo colonial supérstite”: Glave 2004: 126). Concretamente, se narra en primera persona el encuentro con unas monjas, lo que incluye la representación de la interacción comunicativa correspondiente, en la que se registran varios fenómenos interesantes. En la imitación del habla de las monjas aparece el quechuismo achachau, integrado (hasta la actualidad) como interjección en el español cuzqueño, mientras que en la narración en boca del Duende se representa un rasgo seguramente ya estigmatizado diastrática y/o diafásicamente, la epéntesis de /i/ en dijieron, y, en la alocución con las monjas, la representación del paradigma-v:

(37) —“ ¡Achachau, Santisima Trinidad!” —Dijieron cuando me sintieron caer dentro.

Mas yo, con mi flema acostumbrada, las peroré de esta suerte — "No temáis, hijas del dolor; el Duende está con vosotras. Decid vuestras penas" (El Duende $N^{\circ} 4$, Cuzco, 16 de abril de 1830, en Glave 2004: 127)

También como publicación periódica dentro de un periódico (en este caso, El Comercio) vio la luz la novela El Padre Horán de Narciso Aréstegui (Huaro, Cuzco, 1820 - Puno, 1869), ambientada en el Cuzco y aparecida en la fecha temprana de 1848, por lo que a 
menudo se la considera primera novela peruana (Glave 2004: 216; Tamayo Vargas 1977: 32-39). En ella encontramos un ejemplo más interesante que los anteriores: en la medida en que ustedes y vosotros llegan a alternar (a través de las formas verbales de sus respectivos paradigmas) en la misma interlocución entre una mujer, que había estado dispuesta a agredir en la calle al anciano que considera asesino de su sobrina, y la gente que pasaba por la calle y que impidió el ataque; la forma verbal correspondiente a ustedes se usa para el acto directivo de mandato inicial y la correspondiente a vosotros para un acto declarativo con un componente comisivo:

(38) ¡Llévenme!... - repetía Carlota mirando a las personas que estaban más cerca de ella-Seréis testigos... de que yo quería quitar la vida a ese viejo asesino... sí, asesino de mi sobrina (El Padre Horán, 1848, p. 118)

En el marco de la hipótesis, expuesta al principio de este apartado, según la cual el paradigma-u/v resultaría de la sustitución parcial del paradigma-v por parte de ustedes, este tipo de testimonios, con address switching, se deberían considerar un paso previo a la posible combinación de formas de los distintos paradigmas o address mixing (como en los ejemplos de (29)-(33), que sería previo, a su vez, a la constitución de un paradigma híbrido estable, como el que estudiamos aquí).

Avanzando unas décadas, en la literatura realista peruana andina de fines del siglo XIX, representada principalmente por la cuzqueña Clorinda Matto de Turner, encontramos mayoritariamente o bien el paradigma-u (más frecuente) o bien el paradigma-v (de uso más restringido), aunque hay ya un ejemplo claro del paradigma-u/v. En su novela Índole (1891), encontramos vuestro como parte del paradigma-v en boca de un padre a sus dos hijas (ejemplo 39). Por su parte, en Aves sin nido (1889), vuestro forma parte del tratamiento de una mujer simultáneamente al cura y al gobernador (ej. 40), pero no podemos saber si se trata del paradigma-u/v o del paradigma-v (la única forma alocutiva, aparte del apelativo señores al principio, es precisamente el posesivo vuestro). En cualquier caso, no pasa 
desapercibido el hecho de que, en otras muchas interacciones entre los personajes del pueblo ficticio en el que se desarrolla esta última novela, no aparezca apenas el paradigma-v (solo una vez en boca del cura a los feligreses $)^{21}$, pero sí se registre frecuentemente ustedes (19 veces), por lo que el vuestro de (40) tendría más aspecto de ser parte del paradigma-u/v (por otra parte, lamentablemente, los ejemplos de ustedes no se acompañan de forma de posesivo ninguna):

(39) Ni solas ni abandonadas, hija, puesto que cuando vuestros maridos os dejan, quizá por exigencias de los negocios, aquí está vuestro padre (C. Matto de Turner, Índole, 1891, p. 158)

(40) ¡Triste realidad, señores! ¡Y bien! Vengo a persuadirme de que el vil interés ha desecado también las más hermosas flores del sentimiento de humanidad en estas comarcas, donde creí hallar familias patriarcales con clamor de hermano a hermano. Nada hemos dicho; y la familia del indio Juan no solicitará nunca ni vuestros favores ni vuestro amparo (C. Matto de Turner, Aves sin nido, 1889, p. 20)

El ejemplo claro del paradigma-u/v aparece en sus célebres Tradiciones cuzqueñas (1886) —donde incorpora más elementos (también románticos) aparte de la tradición realista stricto sensu-, si bien el ejemplo corresponde a circunstancias de uso especiales. Se halla en la "tradición” titulada Lo de antaño y representa una escena situada supuestamente en 1693 en la que varios altos cargos civiles y militares del Cuzco son llamados a Lima:

(41) Los acusados cayeron a Lima en día de gracia y el Virrey les dijo: "Un paseíto, amigazos, y vuélvanse en paz a vuestras casas sin perturbar el orden que necesito para dormir tranquilo" (C. Matto de Turner, "Lo antiguo. Época del Vir[r]ey Conde de la Monclova. En que se sabe cómo es prudente sacudir a tiempo las orejas de los mandatarios”. Tradiciones Cuzqueñas, 1886, p. 89)

Cabe advertir, entonces, que la autora entendió que el paradigmau/v era la forma más apta para representar una relación asimétrica de superior a inferior (las palabras del virrey de Lima a las autori-

21 Sí aparece, en cambio, el paradigma-v singular (incluyendo un caso de vuestro), en boca del mismo personaje femenino del ejemplo al tratar en singular al cura. 
dades locales cuzqueñas) en un contexto oficial (recepción oficial) pero en tono desenfadado (manifiesto en otras formas lingüísticas empleadas por el virrey: amigazos), si bien la delimitación social de grupos que activa el vuestro es clara (el virrey de Lima, por una parte; las autoridades provinciales, por otra). El fragmento podría estar intentando remedar - parcialmente, al menos- la lengua de dos siglos antes; más adelante, al final de $\$ 5.3$, veremos cómo la percepción de la autora encaja con la de nuestros informantes cuzqueños de vuestro como un uso "antiguo" o "colonial". En realidad, percepciones de los hablantes/escritores aparte, esta situación invita solo a realizar cuanto antes el trabajo de archivo y comprobar la profundidad histórica real del fenómeno: en buena lógica, la ausencia de testimonios del paradigma-u/v en el siglo transcurrido entre el primer ejemplo del fenómeno - el de los "indios" de Cochabamba (ej. 33) - de 1783, y el primer ejemplo cuzqueño en Matto de Turner (ej. 41), de 1886, es solo provisional; seguramente, además, esta provisionalidad afecte a la fecha de la primera documentación recién indicada.

La situación en el siglo XX, que hemos reconstruido parcialmente a partir de una muestra aleatoria de materiales de la hemeroteca de la Biblioteca Municipal del Cuzco (concretamente, del Diario El Sol y de El Comercio), no difiere sustancialmente de la centuria anterior, en el sentido de que empezamos documentando o bien el paradigma-u o bien el paradigma-v, si bien la situación cambia rápidamente desde mediados de la centuria, cuando el primero desplaza totalmente al segundo. No es esta la ocasión para desarrollar estos problemas, que lógicamente dependen de las distintas tradiciones discursivas que se reúnen en la prensa ${ }^{22}$, pero sí es interesante notar que es precisamente a partir de esa época cuando

22 El desplazamiento del paradigma-v por el paradigma-u es un cambio reconfigurador de muchas tradiciones discursivas que tienen lugar en el nivel de la lengua escrita periodística y que se realiza a partir de formas existentes (el paradigma-u ya tenía presencia en estos textos desde el siglo XIX): las motivaciones por las que las formas propias de unas tradiciones "invaden” a otras son diversas, pero habrá que buscarlas también en la evolución del propio género periodístico. 
empezamos a registrar el paradigma-u/v para algunas nuevas tradiciones discursivas que se forman dentro del universo discursivo de los periódicos, como en el caso de las "notificaciones" procesales (que incluyen un auto de pago) ${ }^{23}$. Esta tradición se configura como parte integrante de la sección de "avisos judiciales" durante los años 70 y después va desapareciendo, junto con toda la sección, en los periódicos del siglo XXI. Estas notificaciones consistieron en la fórmula:

(42) Lo que notifico a Uds. para vuestro conocimiento y fines legales (Diario El Sol, Cuzco, 7 de enero 1978)

Asumimos que la formación de esta regla discursiva concreta (o, cabría decir, esta "discursivización” de vuestro) no se configuró creativamente, sino que lo hizo a partir de reglas idiomáticas (Koch 1997) en las que el paradigma-u/v tenía cierto uso. Nos preguntamos, en todo caso, si la fijación de vuestro en este tipo de tradiciones, no solo en periódicos, sino, en general, en discursos públicos con cierto carácter de oficialidad, pudo haber contribuido a su supervivencia en la zona de Cuzco (o surandina) e incluso haber retroalimentado su uso (ahora por medio de una “idiomatización”) ${ }^{24}$.

\subsection{Contacto cultural y lingüístico}

En el ejemplo (28) ya vimos el testimonio de un informante de Ollantaytambo cuya primera intuición fue relacionar el uso de vuestro con el mestizaje entre incas y españoles, aunque no supiera concretar exactamente esta relación. En la misma localidad, otra

\footnotetext{
23 Las notificaciones son uno de los actos jurídicos procesales claves. A través de ellos se hace saber de forma legal a una de las partes del juicio el cumplimiento de un acto procesal o la resolución correspondiente a dicho juicio. En ellos, el órgano jurisdiccional notifica la resolución al destinatario, el cual quedará, por medio del propio acto de habla (declarativo), advertido legalmente de la comunicación y de la necesidad de cumplir los requisitos legales pertinentes.

24 Sabemos que, en el cambio lingüístico, en general, y en el uso de formas de tratamiento en el Perú y otros países latinoamericanos, en particular, los documentos legales y administrativos tuvieron un papel histórico importante (v. Dankel y Gutiérrez Maté 2020: 334-336)
} 
informante lo relacionaba directamente con el quechua y pensaba que era un rasgo aún más típico de los pueblos de montaña cercanos, donde el quechua tendría un peso aún mayor:

(43) en las partes más arriba de acá el quechua son netos; ya también cuando lo mezclan con el castellano dice... o "ustedes", en vez que diga, a veces le dicen "vuestra"...

La informante tradujo algunos de nuestros ejemplos del español al quechua, utilizando el sufijo quechua de 2P.PL (Soto Rodríguez y Fernández Mallat 2012: 83), pero no pudo concretar la relación exacta por la que el quechua pudo influir sobre el español. No esperábamos que lo hiciera, pues, si hubiera contacto lingüístico, sería indirecto; es decir, en los juicios metalingüísticos de los hablantes parece difícilmente aprehensible la hipótesis de la reorganización completa de las personas de plural que en Dankel y Gutiérrez Maté (2020) explicamos como una "transferencia nocional". Con este concepto queremos dar cuenta de cómo los idiomas pueden influirse mutuamente sin que haya correspondencias unívocas entre los elementos de una y otra lengua. Partimos para ello, entre otros autores, de Johanson (2008) (v. Dankel y Gutiérrez Maté 2020: 341-343). Este autor, que habla de copias selectivas de cuatro tipos — materiales, semánticas (o funcionales, que incluyen también aspectos pragmáticos), combinatorias (como calcos sintácticos) y de frecuencia-, demuestra que, para que haya contacto lingüístico, basta con que los hablantes establezcan una relación de equivalencia entre un elemento (en sentido amplio) de la lengua de origen con un elemento (en sentido amplio) de la lengua meta. Esto va más allá de la típica extensión de significados de una forma dada de una lengua para replicar la amplitud semántica de la forma correspondiente en la otra lengua. En realidad, un contenido nocional se puede expresar mediante el reanálisis de estructuras de otra parte del sistema de la lengua meta, esto es, estructuras cuya función original no consistía (al menos, primariamente) en vehicular tal noción, pero que cuentan con la potencialidad del sistema para generar tal función, lo que lleva a los hablantes a desarrollar nuevas rutinas comunicativas 
por el uso creativo del lenguaje (v. Babel y Pfänder 2014). Además, las funciones semánticas de las copias a menudo no alcanzan el estado de gramaticalización de los modelos, sino que su uso queda determinado pragmáticamente (Johanson 2008: 70).

En el caso de vuestro, propusimos que su uso como indicación del contraste entre dos grupos está vinculado con la reinterpretación de esta forma lingüística del español para transmitir una rutina comunicativa que está totalmente gramaticalizada en quechua: ahora bien, no en la 2P.PL sino en la 1P.PL. Nos referimos a la "clusividad", o sea, la inclusión o exclusión de los oyentes en las acciones o estados de los hablantes, lo que equivale en gran parte a expresar o no el contraste también a nivel psicológico y actitudinal entre hablantes y oyentes o, yendo un paso más allá, entre los grupos en los que hablantes y oyentes se incluyen - grupos cuya identidad se construye también discursivamente-. El quechuahablante acostumbrado a expresar a cada paso la inclusión o no de los oyentes, esto es, a marcar constantemente la relación in-group/ out-group, fue muy coherente al no renunciar completamente a ella en español. Para ello, no inventó nuevas formas de 1P.PL en esta lengua ni transfirió materialmente uno o los dos pronombres del quechua ${ }^{25}$, sino que sacó partido a la existencia de dos formas de 2P.PL — con funciones que no siempre se distinguían claramente en la etapa colonial $(\$ 5.2)$ - , para adaptarlo a las necesidades comunicativas del quechua (necesidades que, a su vez, encuentran su raigambre cultural específica en el mundo andino). La adaptación sería aún más esperable si hubiera en realidad convergencia con el español, es decir, si las alternancias entre formas de 2P.PL en el español de la época tuvieran a veces también el valor secundario contextual de marcar un contraste entre hablantes y oyentes, algo para lo que nos falta aún evidencia diacrónica; además, hemos visto el valor "grupal” del paradigma-v desde fines de la colonia y

\footnotetext{
25 Todos estos tipos de procedimientos, por cierto, serían habituales en la formación de lenguas criollas; de hecho, se registran a menudo en criollos cuyo "sustrato" presenta la distinción inclusivo-exclusivo en la 1P.PL, como el zamboangueño, el Tok Pisin, etc.
} 
durante el siglo XIX (ejemplos (34)-(35)), el cual se acerca en este sentido al uso de contraposición grupal del paradigma-u/v.

El quechua, además, nos da algunas claves para entender que, si bien esta lengua presenta la oposición inclusivo-exclusivo en todas las formas del paradigma gramatical, la distinción es especialmente importante en los posesivos, por lo que al menos esta debió mantenerse en el español de la zona. Las pocas investigaciones sobre el sistema pronominal (posesivo) del quechua indican que, en el plano conceptual, los posesivos transmiten una serie de asociaciones entre las personas y entidades que participan en un evento comunicativo, diferentes del sistema español europeo:

[los morfemas posesivos/relacionales] pueden constituir recursos discursivos importantes para, según la situación, expresar la inclusión o la exclusión y el acercamiento o el alejamiento de un hablante respecto a determinados aspectos; lo cual, a su vez, permite a un hablante atribuir matices afectivos y despectivos a las asociaciones (Soto Rodríguez y Fernández Mallat 2012: 84).

Por este motivo, Soto Rodríguez y Fernández Mallat (2012) no hablan de posesivos sino de marcadores de relaciones. Esta diferencia sutil entre la posesión como está codificada en el español estándar y la "relación" según la concepción cultural andina/quechua ${ }^{26}-$ que estos autores describen con detalle por primera vez- debió jugar un papel importante en la alternancia entre vuestro y $s u$. Las relaciones de clusividad de los participantes del acto comunicativo encuentran en los posesivos uno de sus nichos predilectos; además, nuestras observaciones sobre la alternancia entre las dos formas

\footnotetext{
26 En un trabajo que sigue a Soto Rodríguez y Fernández Mallat (2012), los autores, junto con Juan Carlos Godezzi, que se dedica a la posesión predicativa en los Andes, destacan, en sus conclusiones, que el tipo de relación con los referentes del mundo tiene una fuerte presencia en el uso de estructuras lingüísticas halladas en la población andina, tanto en el quechua como en el español de esta zona (Soto Rodríguez, Fernández Mallat y Godenzzi 2017). Y aunque ellos se refieren en primer lugar a estructuras como el llamado ‘doble posesivo' de los Andes, el principio cultural-cognitivo de que es importante indicar los vínculos y asociaciones entre personas y entidades vale también para la composición de grupos y la relación de ellos con las entidades con que interactúan.
} 
del posesivo como resultado de la distinta conceptualización del grupo de alocutarios por parte del hablante (como entidad cohesiva o como entidad de individuos independientes; véase $\$ 4.2)$ representa justamente una manera de vincular a las personas dentro de un grupo y de asociarlas con las entidades con las que interactúan.

Admitimos que quedan problemas por resolver en el marco de nuestra hipótesis, pero nos resultaría difícil llegar a los usos cuzqueños o surandinos actuales de vuestro solo a partir de los del español colonial. A fin de cuentas, tal vez no sea casualidad que el primer testimonio del paradigma-u/v hallado hasta ahora (ej. 33) corresponda al español de quechuahablantes (de Cochabamba). Queda por determinar si el hecho más general de combinar formas de los paradigmas de vosotros y ustedes de fines del s. XVIII y principios del XIX (ejs. (29)-(33)) estuvo motivado de alguna manera por el contacto lingüístico; en cualquier caso, estas confusiones serían el fondo ideal para una posible reformulación de estas formas conforme a las estrategias discursivas de los quechuahablantes. Por lo que respecta concretamente al Cuzco, todo desarrollo lingüístico está condicionado de algún modo por el hecho de tratarse de un escenario multilingüe: la particular historia de la región (donde el quechua nunca estuvo estigmatizado, salvo quizá en algunas etapas del siglo XX), el orgullo de su identidad mestiza, el "purismo" lingüístico (que afecta primeramente a la variedad utilizada de quechua $y$, por extensión, al español) son claves para entender los desarrollos lingüísticos del español en la zona (Dankel y Gutiérrez Maté 2020: 348-352). En vista de todo ello, creemos que el uso de vuestro guarda relación con el quechua pero que no por ello resulta necesariamente de un "cambio desde abajo".

Quepa volver, en las últimas líneas de este apartado, a algunas percepciones de los propios hablantes con respecto al "mestizaje" e incluso, a partir de este, con la preferencia por vuestro. La informante que produjo (43) dijo también que "el quechua es más lindo que el español, más educado" - una idea bastante extendida en la región-; dado que, en general, el uso de vuestro parece relacionarse con la buena educación (sin duda, se percibe como tal: $\$ 4.3$ ), 
la asociación de esta palabra del español regional con el idioma quechua sería (por lo lindo y lo educado de ambos) completamente natural. De hecho, por lo que respecta a lo "educado", podría haber un fondo de verdad en esta percepción: en el marco de la cultura andina, representada por dos lenguas - la española y la quechua-, la educación se manifiesta también en la separación de grupos, "un poquito limitando" (como vimos en un testimonio de $\$ 4.3$ ). Incluso, la limitación de grupos puede ser un recurso de cortesía lingüística "negativa" (la que cuida la face de los oyentes al no inmiscuirse en sus actuaciones), siendo posible que las culturas andinas recurran más a este tipo de cortesía, mientras que, tal vez, en las culturas de cuña europea se dé primacía a la cortesía positiva (lo que parece razonable en español, dada la vastedad y complejidad —más aún en perspectiva histórica- del dominio de formas pronominales y fórmulas nominales de tratamiento).

Por otra parte, cabe señalar que todos los informantes son conscientes de que el mestizaje es un proceso antiguo que data de la época colonial (abundan las representaciones culturales y artísticas en la región que lo demuestran, a las que los informantes han estado expuestos durante todas sus vidas), por lo que no sorprende que algunos relacionaran el uso de vuestro, considerado mestizo, con esta antigüedad. Por ejemplo, una informante (de origen rural, pero con residencia en la ciudad) mencionó que es precisamente por este mestizaje por lo que en el español cuzqueño hay más elementos del tiempo colonial, a diferencia de lo que sucede, por ejemplo, en Lima, donde - recuperando ahora las palabras del informante de (28)"ya viene algo posterior". De hecho, fue relativamente común la percepción de que vuestro era palabra de la colonia. Curiosamente, parece que el argumento del mestizaje se emplea a menudo para justificar lo que podríamos considerar "arcaísmos"; en estos casos, sin embargo, los hablantes están asumiendo que también los elementos antiguos del español debieron estar quechuizados desde la época antigua. 


\section{Balance y perspectivas}

Quepa, para terminar, una breve recopilación de los hallazgos principales de este trabajo, junto con algunas de las preguntas abiertas. Por lo que respecta al sistema, el vuestro en la región de Cuzco es solo plural, está integrado en el paradigma de ustedes y su uso va más allá de un empleo restringido a unas pocas tradiciones discursivas. En términos de su uso semántico-discursivo y social, presentamos tres valores: un valor discursivo de "contraste", un valor semántico especial dentro de la pluralidad (referencia específica, más "grupal” que simplemente "plural", con posible interpretación distributiva), y un valor socioindexical de "buena formación" o incluso de "calidad personal". Entre ellos, especialmente el valor grupal o, mejor dicho, las diferentes maneras de percibir a un grupo, construyendo sus identidades discursivamente, nos parece la pista más prometedora para entender la alternancia entre vuestro y su. No descartamos que esta variable lingüística tenga también un condicionamiento pragmático (en función de la verbalización o no de la carga ilocutiva (performatividad) y, sobre todo, del tipo de acto ilocutivo), pudiendo incluso haber cierto address switching en contextos públicos y privados (lo que explicaría el "vuestro de regaño" en el ámbito familiar), pero aún faltan datos para extraer conclusiones definitivas.

Por otra parte, hemos identificado los desafíos más pertinentes en cuanto a la presencia del fenómeno en el espacio y en el tiempo. Futuros trabajos habrán de decidir si el fenómeno es cuzqueño, surandino o si tiene incluso mayor extensión y si los valores que adopta vuestro en el discurso en estas otras regiones se parecen en algo a los descritos aquí. En la parte diacrónica, se hace evidente la necesidad de un trabajo de archivo exhaustivo, al tiempo que el modelo de tradiciones discursivas se revela como el marco que mayores garantías ofrece para entender los procesos de cambio implicados. Uno de los problemas históricos de mayor calado es la convivencia del paradigma-u/v con el paradigma-v, de modo que la historia del primero seguramente no pueda entenderse en su 
totalidad sin la del segundo: reviste especial interés, por ejemplo, la relativa semejanza del uso "grupal-ciudadano" del paradigma-v en textos de los siglos XVIII y XIX y el vuestro del paradigma$\mathrm{u} / \mathrm{v}$ actual (en casos como (2), (8), etc.), así como el hecho de que las tradiciones discursivas periodísticas cuzqueñas que surgieron en el XIX (con antecedentes en la centuria anterior) no incorporaron el paradigma-u/v, que hubo de esperar hasta la segunda mitad del siglo XX (la época, también, de abandono definitivo del paradigmav) para aparecer en el marco de otras tradiciones nuevas, propias de la época, por más que a nivel idiomático pudiera haber existido desde mucho antes. Por último, hemos destacado la dependencia de aspectos culturales e identitarios andinos $\mathrm{y}$, particularmente, cuzqueños, como el multilingüismo español/quechua y la idea y orgullo del mestizaje (también como parte de la autopercepción de la población cuzqueña), lo que nos lleva a considerar viable -o incluso necesario- la consideración del influjo del quechua en el origen/mantenimiento del fenómeno estudiado en el español de la región, a modo de transferencia nocional. Lo que, históricamente, el hablante de quechua (también el bilingüe mestizo citadino) se esforzó siempre por mantener fue una estrategia para marcar la contraposición grupal en la interacción discursiva (v. Dankel y Gutiérrez Maté 2020).

El lector familiarizado con la bibliografía sobre tratamientos en español recordará que M. B. Fontanella de Weinberg (1939-1995) -en justicia, una de las figuras más inspiradoras aún hoy para sociolingüistas e historiadores del español de América- presentó en su trabajo póstumo de 1999 el uso de vuestro como posible alternativa de $s u$ en todos los esquemas de tratamientos existentes en América (v. también Fontanella de Weinberg 1992a: 151) y, tal vez, que mucho antes, en 1971, había escrito (suponemos, en referencia al paradigma-u/v) que "encontramos también la mezcla, común en la lengua escrita de América Latina aún en la actualidad, de formas verbales y pronominales correspondientes a ustedes y vosotros" (1971: 511). Lamentablemente, la autora no llegó a desarrollar lo que sus esquemas de tratamientos II-IV sugerían. Más de 
dos décadas después, esperamos que nuestro trabajo contribuya a cubrir esta importante laguna investigativa y que, en el caso ideal, sirva de revulsivo para colegas interesados en el tema. Este trabajo, junto con Dankel y Gutiérrez Maté (2020), presenta evidencias suficientes sobre un fenómeno complejo prácticamente desatendido hasta ahora, al tiempo que comparte una instantánea de un programa de investigación en marcha que sirve para esbozar algunos posibles desarrollos en el estudio de la segunda persona plural en la historia del español de América.

\section{REFERENCIAS BIBLIOGRÁFICAS}

AnIPA, Kormi

2001 A Critical Examination of Linguistic Variation in Golden-Age Spanish. New York: Peter Lang.

Arellano, Ignacio y Andrés Eichmann (eds.)

2005 Entremeses, loas y coloquios de Potosí (Colección del Convento de Santa Teresa). Fráncfort del Meno / Madrid: Vervuert/Iberoamericana.

Aréstegui ZuZunaga, Narciso

[1848] 1960 Elpadre Horán; escenas de la vida del Cuzco. Lima: Editorial Universo.

Babel, Anna M. y Stefan Pfänder

2014 "Doing copying: Why typology doesn't matter to language speakers". En Congruence in Contact-Induced Language Change. Language Families, Typological Resemblance, and Perceived Similarity. Linguae E Litterae. Eds., Juliane Besters-Dilger, Cynthia Dermarkar, Stefan Pfänder y Achim Rabus. Berlín, Boston: De Gruyter, 239-257.

BertolotTi, Virginia

2007 "La cuestión de vuestro/a(s): vitalidad medieval y clásica en el español de Uruguay”. En Estudios de lingüística hispánica. Eds., Virginia Bertolotti, Serrana Caviglia, Sylvia Costa, Mariela Grassi, Marisa Malcuori y María Dolores Muñoz. Cádiz: Universidad de Cadiz, 17-41. 
BERTOLOTTI, Virginia

2020 "The loss of vosotros in American Spanish". En Address in Portuguese and Spanish. Eds., Martin Hummel y Celia dos Santos Lopes. Berlín, Boston: De Gruyter, 291-316.

Brown, Roger y Albert Gilman

1960 "The Pronouns of Power and Solidarity". En Style in Language. Ed., Thomas A. Sebeok. Cambridge, MA: MIT Press, 253-276.

Calderón Campos, Miguel

2015 El español del reino de Granada en sus documentos (14921833). Oralidad y escritura. Berna: Peter Lang.

Calderón Campos, Miguel

2019 "Pérdida del pronombre vosotros y su paradigma". En Estudios de morfosintaxis histórica hispanoamericana. Vol. I: El pronombre. Ed., Juan Sánchez Méndez. Valencia: Tirant, 125162.

Caravedo, Rocío

1996 "Peru”. En Manual de dialectología hispánica: el español de América. Ed., Manuel Alvar López. Barcelona: Ariel, 152-168.

Caravedo, Rocío

2005 "La realidad subjetiva en el estudio del español de América". En El español en América: Aspectos teóricos, particularidades, contactos. Eds., Volker Noll, Klaus Zimmermann y Eva Neumann-Holzschuh. Fráncfort del Meno / Madrid: Vervuert / Iberoamericana, 17-31.

Caravedo, Rocío

2019 "Reflexiones sobre la interrelación entre diacronía y diatopía. A propósito del español de América”. En Tendencias $y$ perspectivas en el estudio de la morfosintaxis histórica bispanoamericana. Eds., Viorica Codita y Mariela de la Torre. Fráncfort del Meno / Madrid: Vervuert / Iberoamericana, $19-42$.

Coseriu, Eugenio

1982 Sentido y tareas de la dialectología. México: UNAM, Instituto de Investigaciones Filológicas, Centro de Lingüística Hispánica. 
Cuervo, Rufino Jose

1876 Apuntaciones criticas sobre el lenguaje bogotano. Segunda edición notablemente aumentada. Bogotá: Imprenta de Echeverria hermanos.

Dankel, Philipp y Miguel Gutiérrez Maté

2020 "Vuestra atención, por favor 'your attention, please'. Some remarks on the usage and history of plural vuestro/a in Cusco Spanish (Peru)". En Address in Portuguese and Spanish. Studies in Diachrony and Diachronic Reconstruction. Eds., Martin Hummel y Celia dos Santos Lopes. Berlín, Boston: De Gruyter, 317-360.

DAVIDSON, Brad

1996 “'Pragmatic weight' and Spanish subject pronouns: The pragmatic and discourse uses of 'tú' and 'yo' in spoken Madrid Spanish”. Journal of Pragmatics. 26, 543-595. <https://doi. org/10.1016/0378-2166(95)00063-1>

FERnÁndez Martín, Elisabeth

2012 "Vosotros/ustedes. Estudio del tratamiento plural en el español dieciochesco". En El español del siglo XVIII. Cambios diacrónicos en el primer español moderno. Ed., María Teresa García Godoy. Berna: Peter Lang, 53-194.

Fontanella De Weinberg, María Beatriz

1971 "El voseo en Buenos Aires en las dos primeras décadas del siglo XIX”. Thesaurus: boletín del Instituto Caro y Cuervo. 26, 3, 495-574.

Fontanella De Weinberg, María Beatriz

1992a El español de América. Madrid: MAPFRE.

Fontanella de Weinberg, María Beatriz

1992b "Fusión de paradigmas, variación y cambio lingüístico. El caso del voseo". En Homenaje a Humberto López Morales. Eds., María Vaquero y Amparo Morales. Madrid: Arco Libros, 185194.

Fontanella De Weinberg, María Beatriz

1999 "Sistemas pronominales de tratamiento usados en le mundo hispánico”. En Gramática descriptiva de la lengua española. Vol. 1. Sintaxis básica de las clases de palabras. Eds., Violeta Demonte y Ignacio Bosque. Madrid: Espasa Calpe, 1399-1426. 
Frago Gracia, Juan Antonio

2010 El español de América en la Independencia. Santiago de Chile: Taurus.

Frago Gracia, Juan Antonio

2011 "El español de América en la Independencia. Adiciones gramaticales I”. Boletín de Filología 46, 1, 47-74. <https://doi. org/10.4067/S0718-93032011000100002>

García Godoy, María Teresa

2012 "El tratamiento de merced en el español del siglo XVIII". En El español del siglo XVIII. Cambios diacrónicos en el primer español moderno. Ed., María Teresa García Godoy. Berlin: Peter Lang, 111-152.

Glave, Luis Miguel

2004 La república instalada: Formación nacional y prensa en el Cuzco 1825-1839. Lima: Institut français d'études andines.

GodenZZi, Juan Carlos

1995 "Discurso y actos de rebelión anticolonial: Textos políticos del silgo XVIII en los Andes”. En Del siglo de oro al siglo de las luces: lenguaje y sociedad en los Andes del siglo XVIII. Ed., Cesar Itier. Cusco: Centro de Estudios Regionales Andinos Bartolomé de Las Casas, 59-88.

Gutiérrez Maté, Miguel

2013 Pronombres personales sujeto en el español del Caribe: Variación e historia. Tesis Doctoral, Departamento de Lengua Española, Universidad de Valladolid. <http://uvadoc.uva.es/ handle/10324/2517>

Gutiérrez Maté, Miguel

2019 "Palenquero Creole: The syntax of second person pronouns and the pragmatics of address switching". En It's not all about you - new perspectives on address research. Eds., Bettina Kluge y María Irene Moyna. Ámsterdam / Filadelfia: John Benjamins, 161-190.

Gutiérrez Maté, Miguel

2020 "De Palenque a Cabinda: un paso necesario para los estudios lingüísticos afroiberorrománicos y criollos”. En Mundos caribeños - Caribbean Worlds - Mondes Caribéens. Eds., Gabriele 
Knauer, Alexandra Ortiz Wallner y Ineke Phaf-Rheinberger. Fráncfort del Meno / Madrid: Vervuert / Iberoamericana, 105138.

Hartmann, Katharina y Malte Zimmermann

2007 "In Place - Out of Place: Focus in Hausa”. En On Information Structure: Meaning and Form. Eds., Kerstin Schwabe y Susanne Winkler. Ámsterdam/Filadelfia: John Benjamins, 365-403.

Hildebrandt, Martha

20111000 palabras y frases peruanas. Lima: Espasa

HildebrandT, Martha

2012 El habla culta (o lo que debiera serlo). Lima: Espasa.

Hummel, Martin

2010 "Reflexiones metodológicas y teóricas sobre el estudio de las formas de tratamiento en el mundo hispanohablante, a partir de una investigación en Santiago de Chile". En Formas y fórmulas de tratamiento en el mundo bispánico. Eds., Martin Hummel, Bettina Kluge y María Eugencia Vázquez Laslop. México DF: El Colegio de México/Karl-Franzens-Universität Graz, 101-162.

Hummel, Martin

2020 "Diachronic research on address in Portuguese and Spanish". En Address in Portuguese and Spanish. Studies in Diachrony and Diachronic Reconstruction. Eds., Martin Hummel y Celia dos Santos Lopes. Berlín, Boston: De Gruyter, 7-70.

JOHANSON, Lars

2008 "Remodeling grammar. Copying, conventionalization, grammaticalization". En Language contact and contact languages. Eds., Peter Siemund y Noemi Kintana. Ámsterdam \& Filadelfia: John Benjamins, 61-79.

KaBATEK, Johannes

2005 “Tradiciones discursivas y cambio lingüístico”. Lexis. 29, 2, 151-177.

Koch, Peter

1997 "Diskurstraditionen: zu ihrem sprachtheoretischen Status und ihrer Dynamik". En Gattungen mittelalterlicher Schrift- 
lichkeit. ScriptOralia. Eds., Barbara Frank, Thomas Haye y Doris Tophinke. Tubinga: Narr (ScriptOralia 99), 43-79.

Koch, Peter y Wulf Oesterreicher

[1990] 2011 Gesprochene Sprache in der Romania: Französisch, Italienisch, Spanisch. 2nd. Berlín, Boston: De Gruyter.

LAMBRECHT, Knud

1994 Information structure and sentence form. Topic, focus, and the mental representations of discourse referents. Cambridge: Cambridge University Press.

Lara Bermejo, Víctor

2015 "Los tratamientos de 2PL en Andalucía occidental y Portugal: estudio geo- y sociolingüístico de un proceso de gramaticalización”. Tesis Doctoral, Departamento de Filología Española, Universidad Autónoma de Madrid. <http://www.infoling. org/repository/PhDdiss-Infoling-22-7-2015.pdf>

Lara Bermejo, Víctor

2020 "Forms of address in the south-western Sprachbund of the Iberian Peninsula: One hundred years of evolution in western Andalusian Spanish and European Portuguese”. En Address in Portuguese and Spanish. Eds., Martin Hummel y Celia dos Santos Lopes. Berlín, Boston: De Gruyter, 71-110.

Matto de Turner, Clorinda

[1886] 1976 Tradiciones cuzqueñas completas. Lima: Peisa.

Matto de Turner, Clorinda

[1889] 1973 Aves sin nido. Lima: Peisa.

Matto de Turner, Clorinda

[1891] 1974 Índole. Lima: Instituto Nacional de Cultura.

Morgan, Terrell A. y Scott A. Schwenter

2016 "Vosotros, ustedes, and the myth of the symmetrical Castilian pronoun system". En Inquiries in Hispanic Linguistics - From theory to empirical evidence. Eds., Alejandro Cuza, Lori Czerwionka y Daniel Olson. Ámsterdam / Filadelfia: John Benjamins, 263-280. 
Morgan, Terrell A. y Scott A. Schwenter

en prensa "Vosotros versus Ustedes: Asymmetries in 2PL Pronouns across Spanish Dialects". En Handbook of Variationist Approaches to Spanish (manuscrito, versión del 14.8.2020).

Narbona Jiménez, Antonio; Rafael Cano Aguilar; y Ramón MorilloVelarde Pérez

2011 El español hablado en Andalucía. $3^{a}$ ed. Sevilla: Universidad de Sevilla, Secretariado de Publicaciones.

Oesterreicher, Wulf

2010 "Sprachliche Daten und linguistische Fakten - Variation und Varietäten. Bemerkungen zu Status und Konstruktion von Varietäten, Varietätenräumen und Varietätendimensionen”. En Näbe und Distanz im Kontext Variation-linguistischer Forschung. Eds., Vilmos Ágel y Mathilde Hennig. Berlín, Boston: De Gruyter, 23-62.

Palomino Valdivia, Claudia y Roberto Ojeda Escalante

2016 Criándonos entre plantas y hombres. Saberes agrícolas de Chinchaypucyo (Anta - Cusco). Cusco: CRESPIAL/UNESCO.

Preston, Dennis R.

1999 "A Language Attitude Approach to the Perception of Regional Variety”. En Handbook of Perceptual Dialectology. Vol. 1. Ed., Dennis R. Preston. Ámsterdam / Filadelfia: John Benjamins, 359-373.

REAL Díaz, José Joaquín

1970 Estudio diplomático del documento indiano. Madrid: Dirección de Archivos Estatales.

Rivarola, José Luis

2005 "Sobre los orígenes y la evolución del español de América". En El español en América: Aspectos teóricos, particularidades, contactos. Eds., Volker Noll, Klaus Zimmermann y Ingrid Neumann-Holzschuh. Fráncfort del Meno / Madrid: Vervuert / Iberoamericana, 33-48.

SoLé, Yolanda R.

1970 "Correlaciones socio-culturales del uso de «tú» / «vos» y «usted» en la Argentina, Perú y Puerto Rico”. Thesaurus: boletín del Instituto Caro y Cuervo. 25, 2, 161-195. 
Soto Rodríguez, Mario y Victor Fernández Mallat

2012 "Marcando referencias y vínculos en el español andino: A propósito del llamado doble posesivo". En El español de los Andes: estrategias cognitivas en interacciones situadas. 41. Neue Romania. Eds., Philipp Dankel, Victor Fernández Mallat, Juan Carlos Godenzzi y Stefan Pfänder. Múnich: Lincom, 57-88.

Soto Rodríguez, Mario; Victor Fernández Mallat; y Juan Carlos GODENZZI

2017 "Posesión predicativa andina: recursos de relación y 77 asociación en zonas de contacto". En Cuestiones de sociolinguロística: aproximaciones a la lengua en uso. Ed., Adriana Speranza. Moreno: UNM Editora.

STEFFEn, Joachim

2010 "El tratamiento en Uruguay". En Formas y fórmulas de tratamiento en el mundo hispánico. Eds., Martin Hummel, Bettina Kluge y María Eugenia Vázquez Laslop. Ciudad de México: El Colegio de México, 449-464.

Tamayo Vargas, Augusto

1977 Literatura peruana. Lima: Librería Studium.

Uber, Diane R.

2011 "Forms of Address: The Effect of the Context". En The Handbook of Hispanic Sociolinguistics. Ed., Manuel DíazCampos. Oxford: Wiley Blackwell, 244-262.

VARgas, José Santos

1982 Diario de un comandante de la Independencia Americana (1814-1825). [Transcripción, introducción y notas de Gunnar Mendoza]. Ciudad de México: Siglo XXI.

VÁzQuez Laslop, María Eugenia

2012 "Títulos nobiliarios e identidad a debate en el primer congreso mexicano (1822)”. En Alteridad y aliedad. La construcción de la identidad con el otro y frente al otro. Eds., Sabine Pfleger, Joachim Steffen y Martina Steffen. Ciudad de México: Universidad Autónoma Nacional de México, 167-191.

WAGNER, Claudio

1996/7 "Sobre el posesivo vuestro en el español de Chile". Anuario de Lingüistica Hispánica. 12-13, 855-861. 


\section{ZWIERLEIN, Cornel}

2009

"Vom Anfang und vom Ende der Frühen Neuzeit - oder: Brannte Konstantinopel 1870 in der Moderne und London 1666 in der Frühen Neuzeit?”. Mitteilungen des Sonderforschungsbereichs 573. "Pluralisierung und Autorität in der Früben Neuzeit (15-17. Jh.)”. 1, 22-31.

Zamora Salamanca, Francisco José

2006 "Usos de segunda persona plural en traducciones hispanoamericanas". En Haciendo Lingüística. Homenaje a Paola Bentivoglio. Eds., Mercedes Sedano, Adriana Bolívar y Martha Shiro. Caracas: Universidad Central de Venezuela. 603-614.

Recepción: 22/09/2020 Aceptación: 22/10/2020 